\title{
تطويروحدة تعليمية من كتاب الجغر افيا للصف الثامن في ضوء عادات العقل وقياس أثرها في التفكير الإبداعي لدى الطالبات في الأردن
}

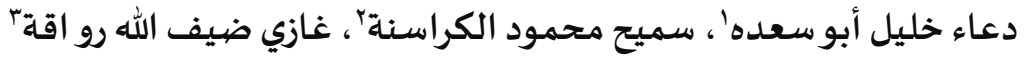

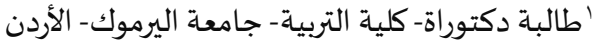

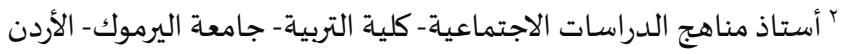 \\ "أستاذ مناهج وطرق تدريس تعليم مهني شامل- كلية التربية- جامعة اليرموك- الأردن الداسن
}

${ }^{1}$ doaa.saada88@yahoo.com, ${ }^{2}$ s.m.karasneh@yu.edu.jo, ${ }^{3}$ Ghazi.Rawagah@yu.edu.jo

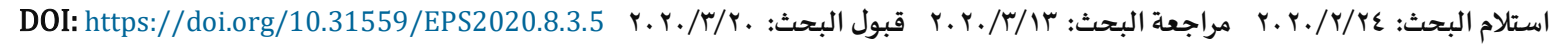

هدفت هذه الدراسة إلى تطوير وحدة تعليمية من كتاب الجفرافيا للصف الثامن في ضوء عادات العقل وقياس أثرها على التفكير الإبداعي

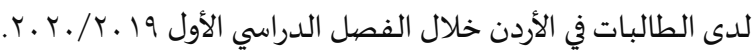

ولتحقيق أهداف الدراسـة تم اعتماد المنهج شبه التجريبي، واستخدمت أداة الدراسـة المتمثلة في اختبار التفكير الإبداعي، حيث تم التحقق

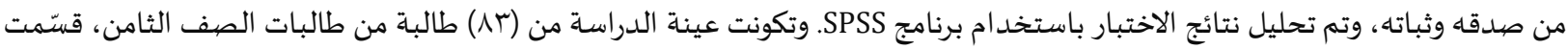

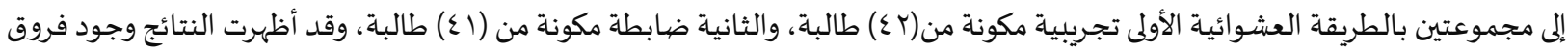

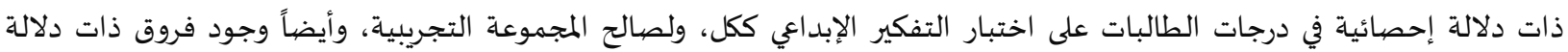

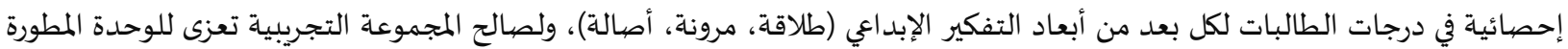
وفق عادات العقل، وقدّم الباحثون مجموعة من التوصيات. الكلمات المفتاحية: تطوير وحدة تعليمية؛ عادات العقل؛ التفكير الإبداعي.

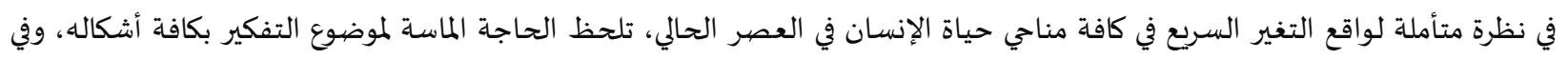

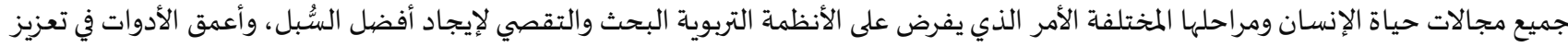

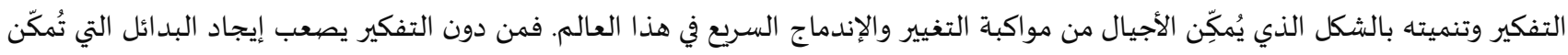

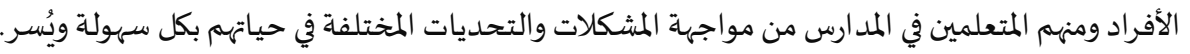

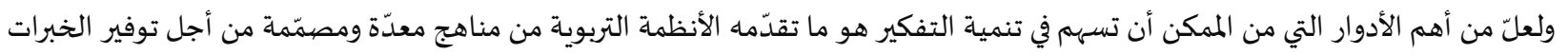

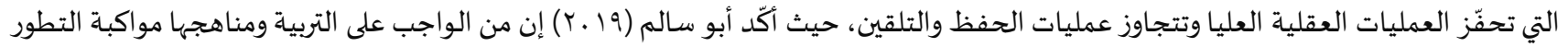

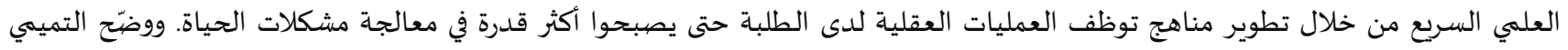

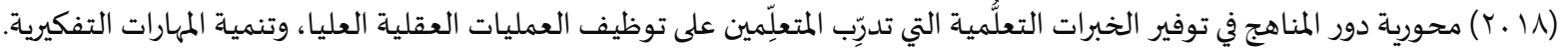

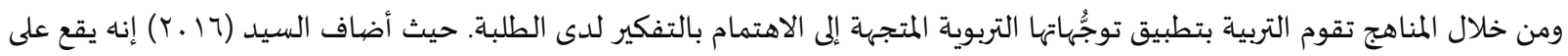

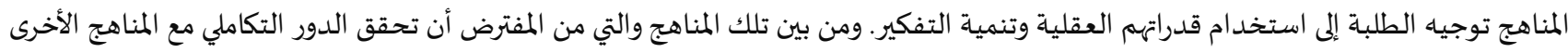

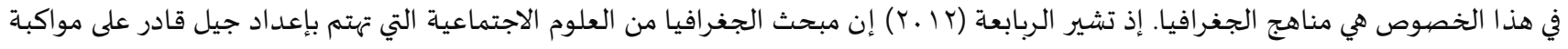

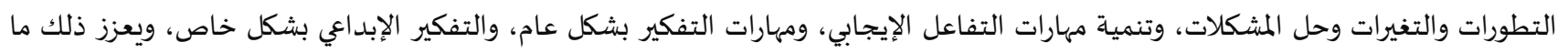


أشار إليه جون (John,2000) أن مادة الجغرافيا قادرة على إكساب الطلبة مهارات التفكير من أجل التوصل لحلول للمشكلات التي تواجههم. كما أكدت ألهات

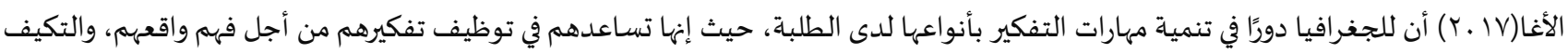

مع الظروف المحيطة بهم، والتعامل مع الظروف والمشكلات التي قد تواجهيهم مستقبلاً.

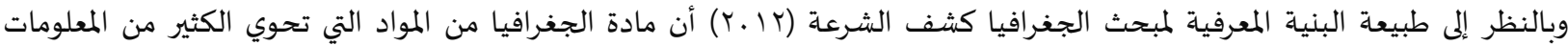

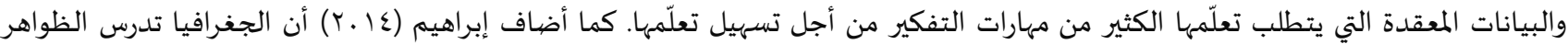

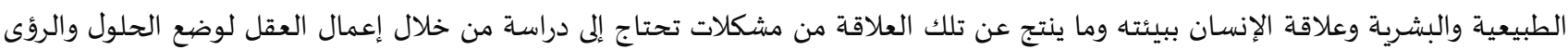
المستقبلية لمواجهتها من خلال استخدام عادات العقل.

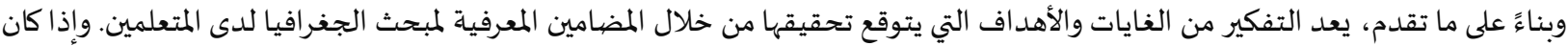

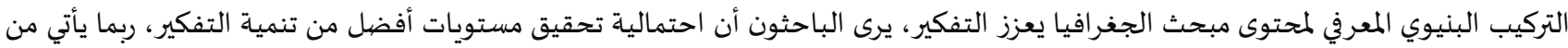

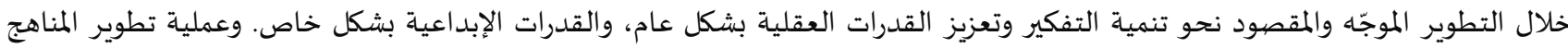

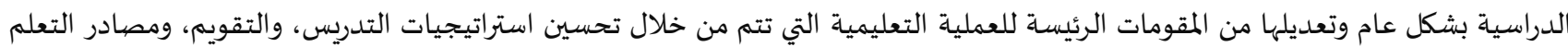

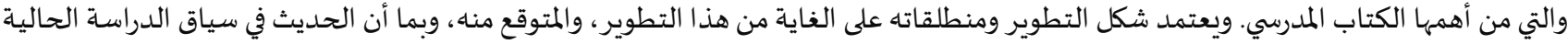

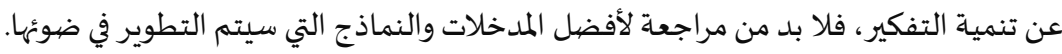

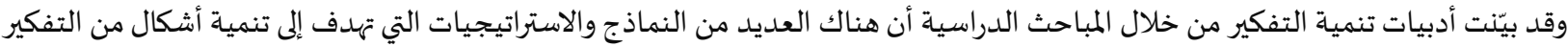

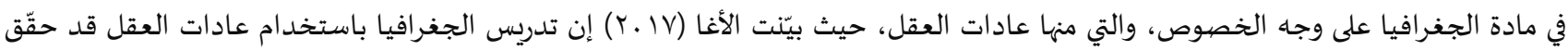

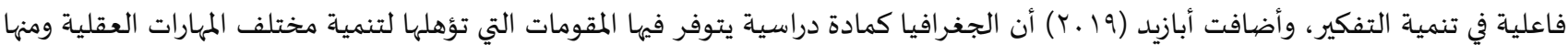

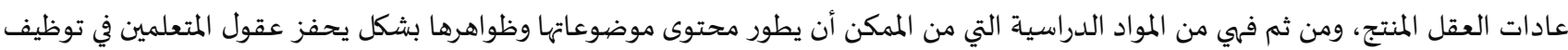

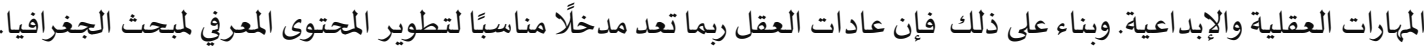

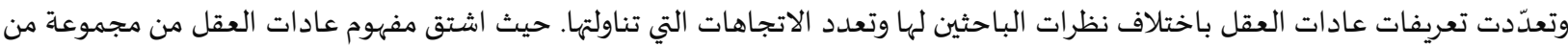

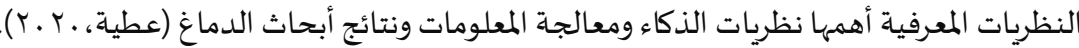

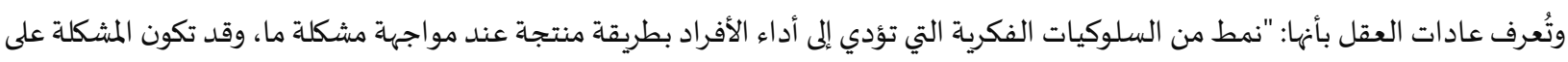

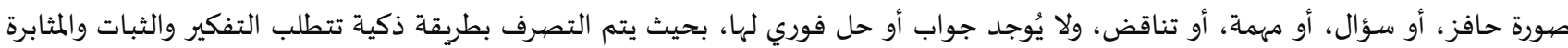
والإبداع، وتصبح عادة لدى الأفراد نتيجة تكرار ممارستها "(Costa, \& Kallick,2009:16).

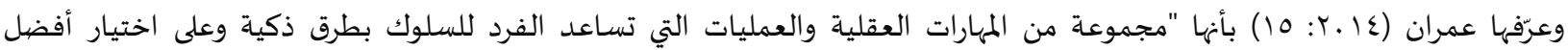
الإستجابات، عند مواجهة خبرة جديدة، أو موقف ما، أو مشكلة معينة، وتطبيق سلوك بفاعلية والمداومة على هذا النهج، وهي تشمل العقل والوجدان

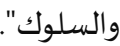

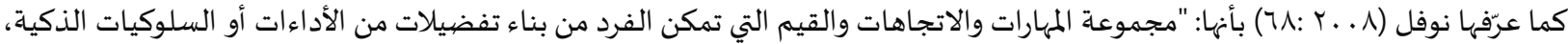

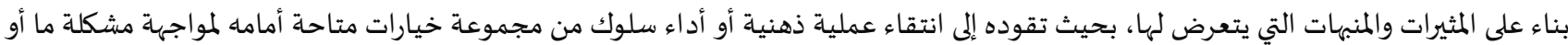

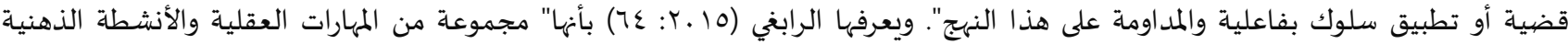

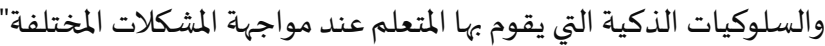

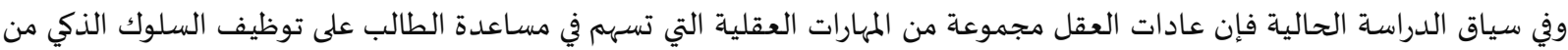

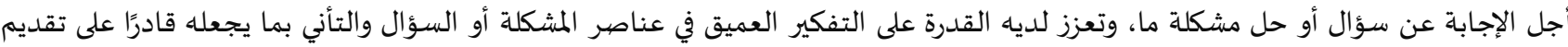
العديد من الأفكار أو الحلول المتنوعة للموقف أو أو المشكلة.

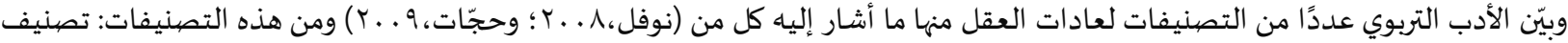

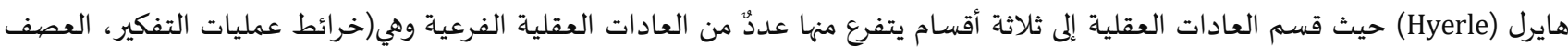
الذهني، المنظمات الشكلية)، وهناك تصنيف مارزانو (Marzano) حيث أطلق علهيا العادات العقلية المنتجة وهي ( التنظيم الذاتي، التفكير الناقد،

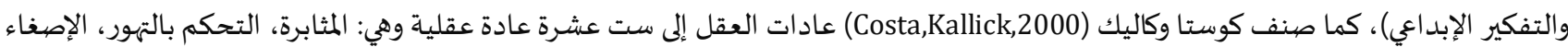
بفهم وتعاطف، التفكير بمرونة، التفكير حول التفكير، الكفاح من أجل الدقة، التساؤل وطرح المشكلات، تطبيق المعارف الماضية على أوضاع جديدة،

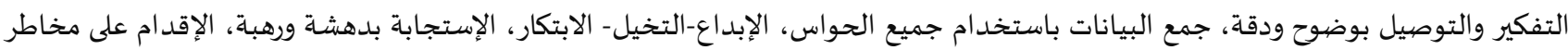

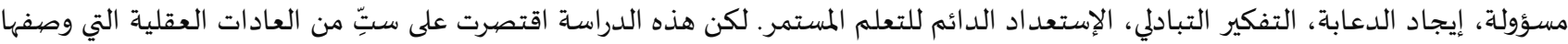
كوستا وكاليك (Costa\&Kallick,2000) وهي: (التفكير بمرونة، المثابرة، التساؤل وطرح المشكلات، الإستجابة بدهشة ورهبة، التفكير التبادلي، والتحكم 


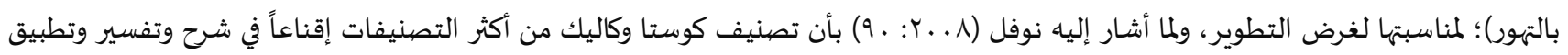

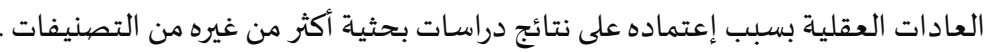

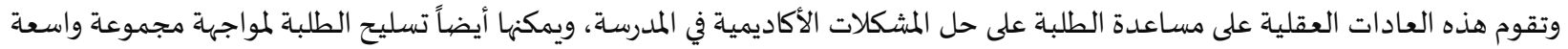

من التحديات طوال حياتهم، وتشجع الطلبة ليصبحوا نشطين وفضوليين في مواجهة التحديات بدلا من السلبية (Boyes,\&Watts, 2009).

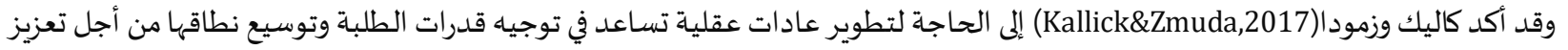

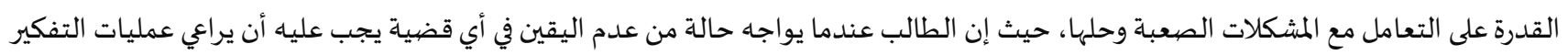

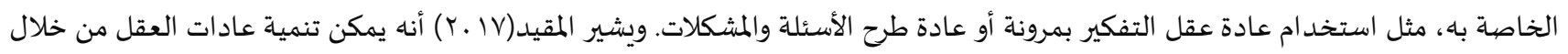
بعض الأنشطة التدريبية، ودمجها مع المحتوى المعرفي للمواد الماد الدراسية. وتأسيساً على ذلك، من الممكن تضمين عادات العقل في مادة الجفرافيا، من خلال تطوير وحدات دراسية في ضوائها؛ لما لها أهمية في تطوير مهارارات

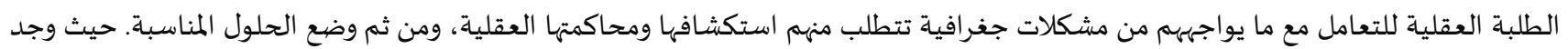

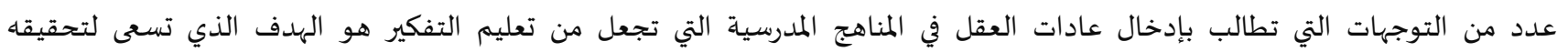

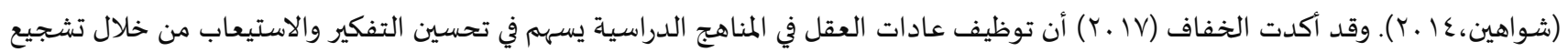

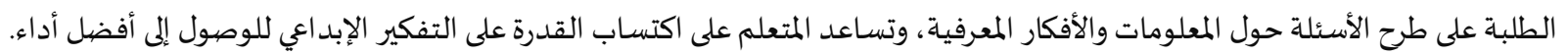

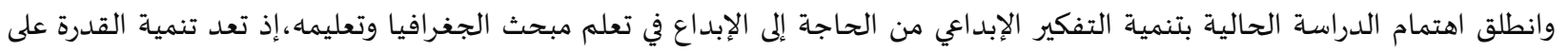

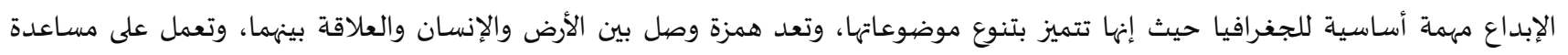

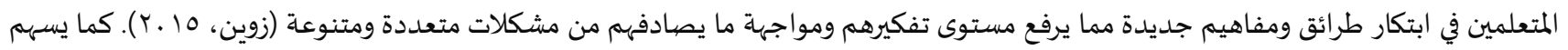

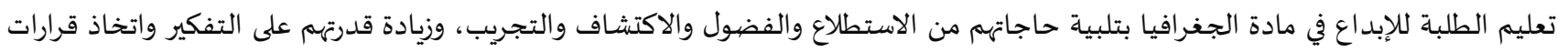

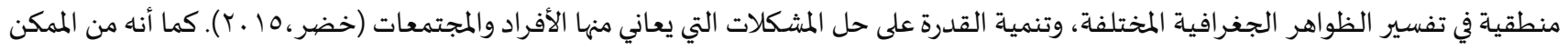

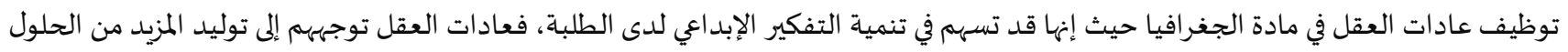

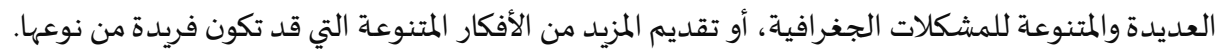

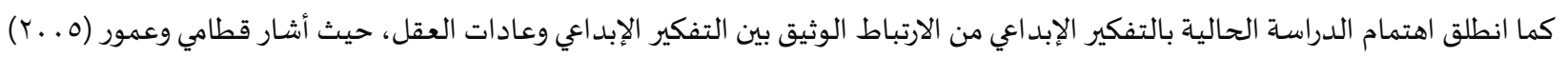

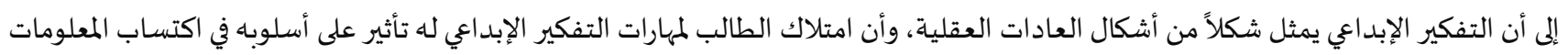

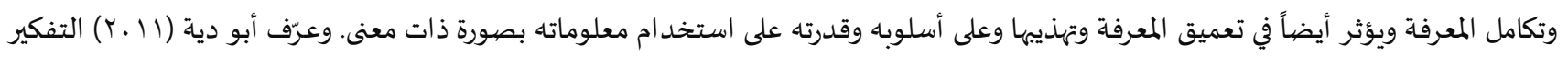

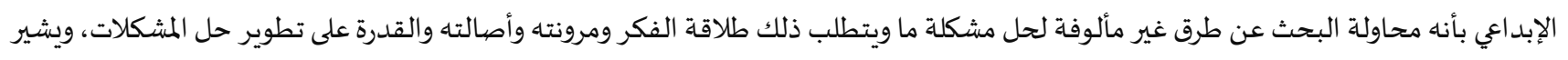

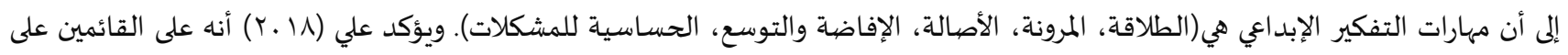

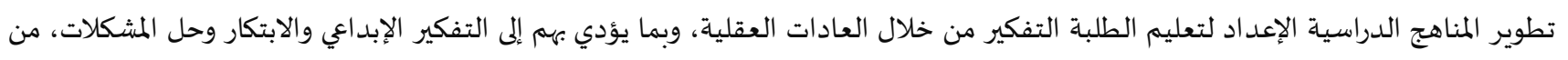

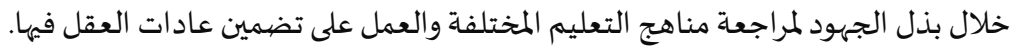

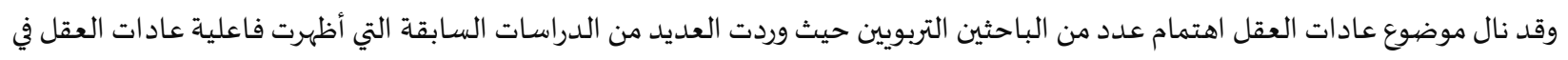

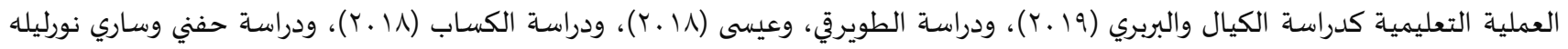

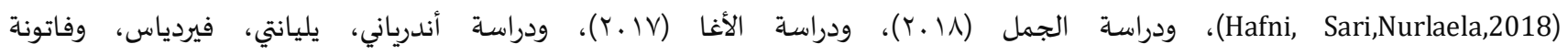

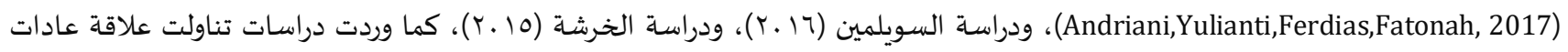

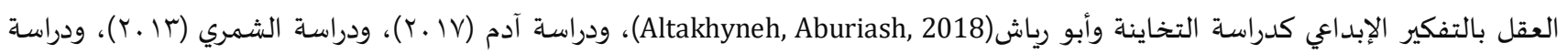

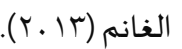

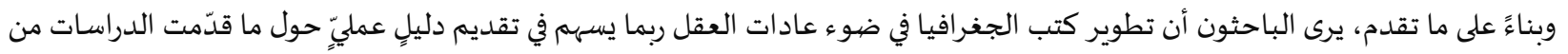

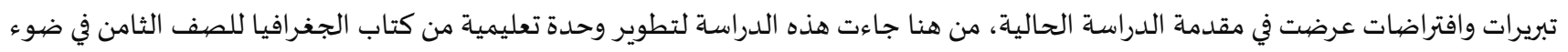
عادات العقل وقياس أثرها في التفكير الإبداعي لدى الطالبات.

مشكلة الدراسة وأسئلتها:

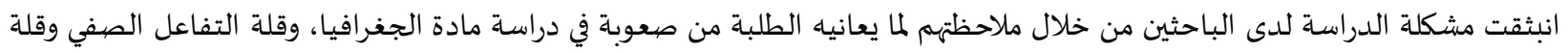

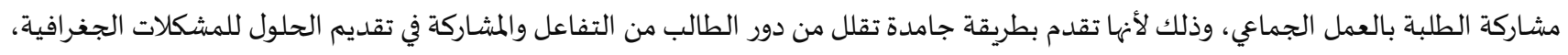
إنما في الغالب تقدم بطريقة تعتمد على الحفظ والتلقين. 
وجاءت هذه الدراسة استجابة لرسالة وزارة التربية والتعليم (19 ـ ب) بضرورة تطوير مناهج التعليم بحيث تراعي التفكير، وتمكن من إيجاد متعلم بشخصية متكاملة قادرة على الإبداع، ودافعة نحو المشاركة بمسؤولية وإنتاجية عالية.

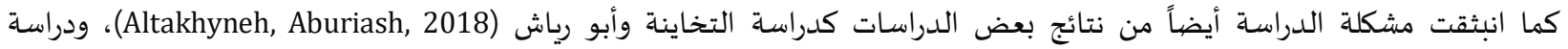

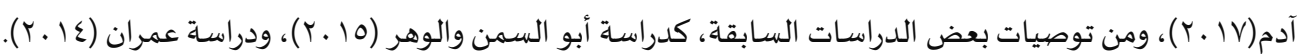

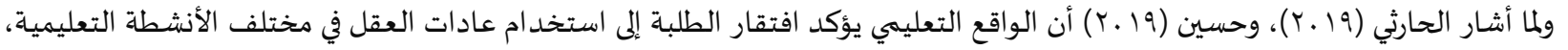

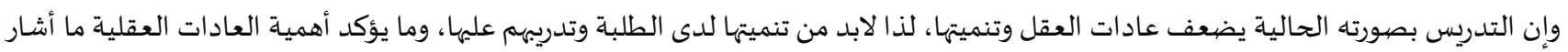
إليه قطامي، عمور(ب . . ب) بأن استخدام العادات العقلية تشجع على ممارسة مهارات التفكير الإبداعي الذي يعد شكلًا من أشكال العادات العقلية.

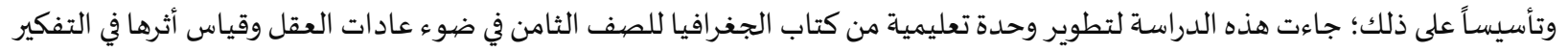

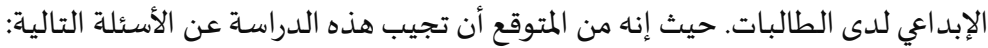

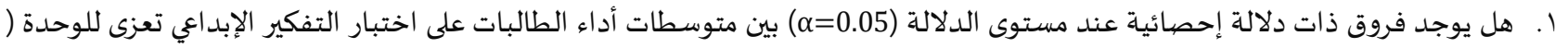

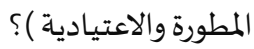
r. هل يوجد فروق ذات دلالة إحصائية عند مستوى الدلالة (م=0.05) بين متوسطات أداء الطالبات على أبعاد التفكير الإبداعي(طلاقة، مرونة،

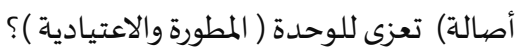

أهمية الدراسـة: - n

ظهرت اتجاهات حديثة تدعو إلى الاهتمام بالتفكير في مادة الجغرافيا واستخدامه في مواجهة المشكلات الجغرافية وتقديم الحلول لها، فعادات العقل من الموضوعات التي قد تسهم في تنمية التفكير لدى الطلبة من خلال إثارة مشكلات توجههم إلى التفكير في إيجاد حلول لها، وقد تفيد هذه الدراسة الفئات التالية:

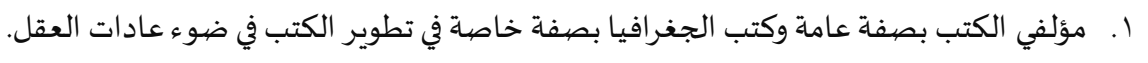
r r معلمي الجغرافيا من أجل استخد ام عادات العقل في التدريس. r. قد تسهم هذه الدراسة في إثراء المعرفة لدى الباحثين في مجال توظيف عادات العقل في تدريس مناهج الجغرافيا ولحثهم لإجراء بحوث تتناول عادات العقل في العملية التعليمية ولجميع المواد الدراسية.

التعريفات الإجر ائية:

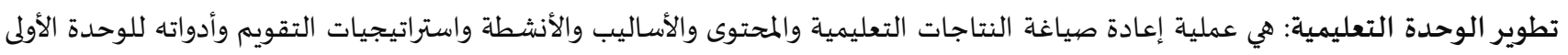
بعنوان (العوامل الطبيعية وأثرها في السكان)، من كتاب الجغرافيا للصف الثامن الأساسي في ضوء عادهادات العقل.

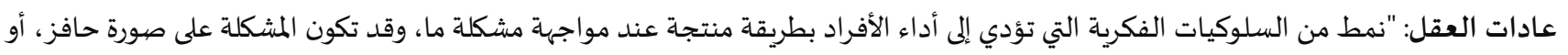
سؤال، أو مهماة، أو تناقض، ولا يُوجد جواب أو حل فوري لها، بحيث يتم التصرف بطريقة ذكية تتطلب التفكير والثبات والمثابرة والإبداع، وتصبح عادة لدى الأفراد نتيجة تكرار ممارستها"(Costa, \& Kallick,2009:16).

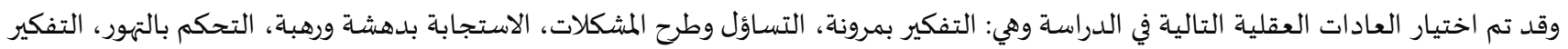
التبادلي، والمثابرة ، وتوضيحها إجرائيا كالتالي :

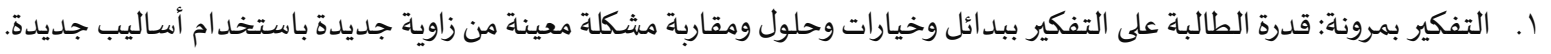
r. التساؤل وطرح المشكلات: قدرة الطالبة على طرح التساؤلات المتعددة حول مشكلة ما، وتوليد عدد من البدائل لحل هذه المشكلة.

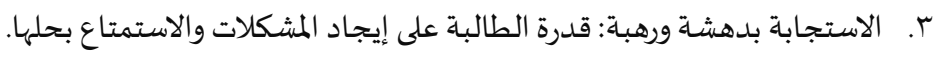
ع. التحكم بالتهور: التأني والتفكير قبل الإقدام على حل المشكلات المطروحة في الدروس، وتأجيل إعطاء الحكم الفوري .

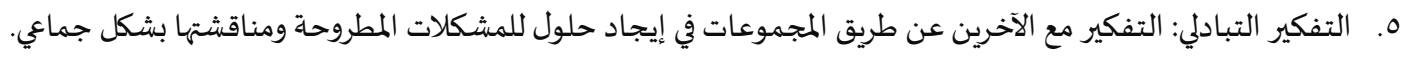
7 ا. المثابرة: الالتزام بالمهمة الموكلة للطالبات إلى حين اكتمالها وعدم الاستسلام بسهولة، والبحث عن حلول وبدائل أخرى في حال عدم نجاح إحدى البدائل والحلول. التفكير الإبداعي : ويعرّف إجرائياً بالدرجة التي تحصل عليها الطالبات في الاختبارين القبلي والبعدي استناداً إلى اختبار التفكير الإبداعي ضمن المكونات

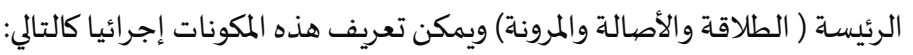

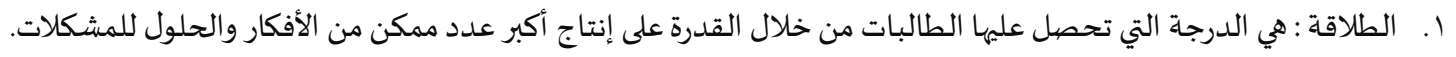

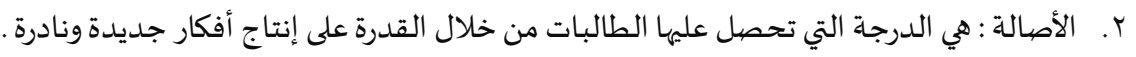


r. المرونة : هي الدرجة التي تحصل عليها الطالبات من خلال القدرة على إنتاج عدد من الأفكار المتنوعة حول الموقف أو المشكلة.

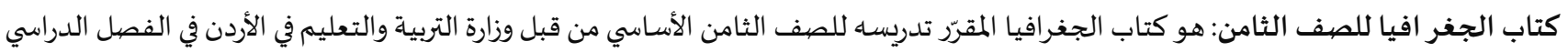

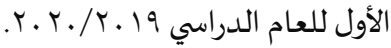

حدود الدراسـة: الحدود البشرية والمكانية: اقتصر تطبيق الدراسة على طالبات الصف الثامن الأساسي في مديرية منطقة الزرقاء الأولى من مدرسة زينب الهلالية الأساسية للبنات.

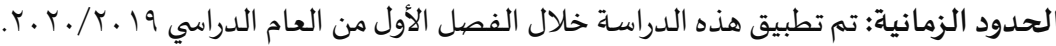

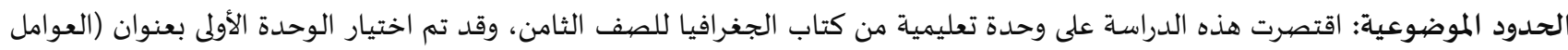

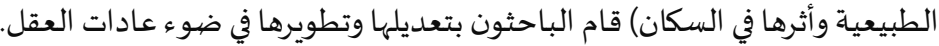

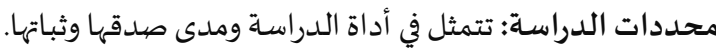

الطريقة والإجراءات:

منهجية الدراسـة:

تم استخدام المنهج شبه التجريبي بتصبميم المجموعات غير المتكافئة القبلي-البعدي باعتماد مجموعتين الأولى تجريبية والأخرى ضابطة؛ وذلك لقياس أثر تطوير وحدة تعليمية من كتاب الجغرافيا للصف الثامن في ضوء عادات العقل في التفكير الإبداعي لدى الطالبات، حيث تمّ تطبيق الوحدة

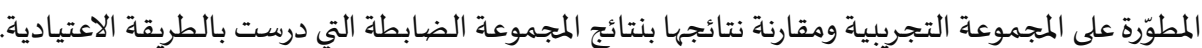

عينة الدراسة: تم اختيار أفراد الدراسـة عشوائياً من مدرسة زينب الهلالية الأسـاسية للبنات التابعة لمديرية التربية والتعليم لمنطقة الزرقاء الأولى، وتكونت عينة الدراسـة من(r)) طالبة، تم توزيعها في مجموعتين الأولى تجريبية عدد أفرادها (r乏) طالبة، وقد درست المجموعة التجريبية الوحدة الأولى (العوامل

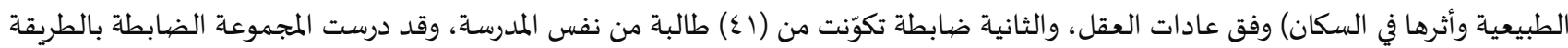

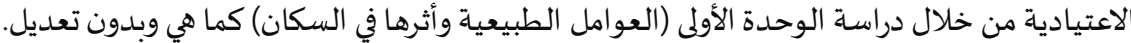

أداة الدراسـة:

اختبار التفكير الإبداعي

تم إعداد اختبار التفكير الإبداعي حيث تمت صياغتاه بما يتناسب مع هذه الدراسة حيث تم الرجوع إلى الأدب النظري والدراسات السابقة

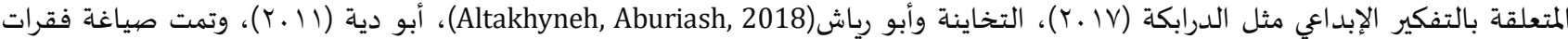

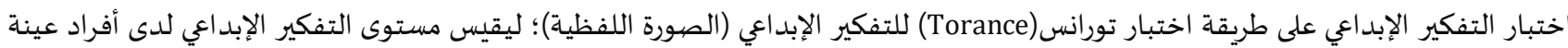

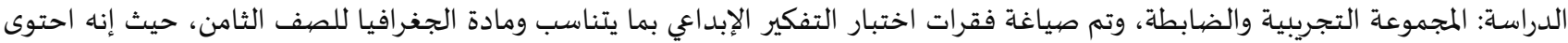
عدة أنشطة فرعية تم إعدادها لتكون مناسبة لمجال الدراسة وبلغ عددها (7) أسئلة موزعة على ثلاثة أبعاد من أبعاد التفكير الإبداعي وهي (الطلاقةة،

الأصالة، المرونة).

صيدق اختبار التفكير الإبداعي

للتحقق من صدق الاختبار الإبداعي تم عرضيه على مجموعة من المحكمين عددهم (9) من أعضاء هيئة التدريس في مجال مناهج الدراسات الاجتماعية وأساليب تدريسها، وفي مجال الجغرافيا من أجل أخذ وجهات نظرهم حول مناسبته من حيث الصياغة، ولمستوى الطالبات، وقابلية

ثبات اختبار التفكير الإبداعي

للتحقق من ثبات اختبار التفكير الإبداعي تم تطبيقه على عينة استطلاعية من خارج عينة الدراسة من طالبات الصفف الثامن الأساسي مكوّنة من ( (Y) طالبة، بطريقة الاختبار وإعادة الاختبار (test-retest)، وإعادة تطبيقه بفارق زمني مدته أسبوعين بين التطبيقين، ومن ثم تم حساب معامل

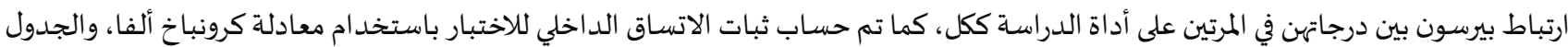
(1) يبين معامل الاتساق الداخلي وثبات الإعادة للأبعاد والأداة ككل. 


\begin{tabular}{|c|c|c|}
\hline ثبات الإعادة & ثبات الاتساق الداخلي & المجال \\
\hline . &., 9 & الطلاقة \\
\hline .,$\wedge \varepsilon$ & ., A & المرونة \\
\hline . $\mathrm{V9}$ &., 11 & الأصالة \\
\hline . 17 &., 9 . & التفكير الإبداعي ككل \\
\hline
\end{tabular}

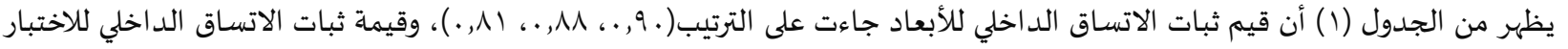

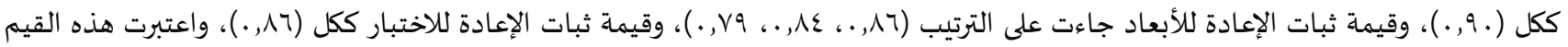

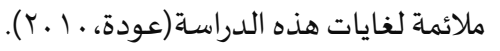

مادة الدراسـة: الوحدة التعليمية المطورة

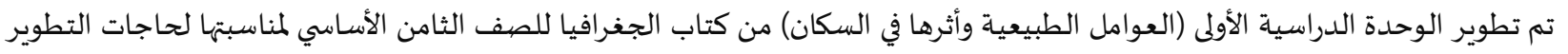

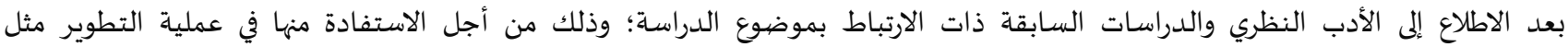

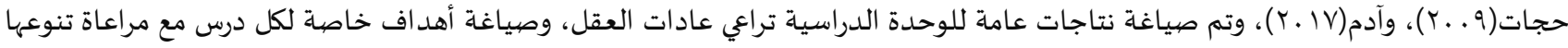

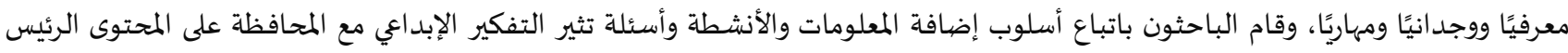

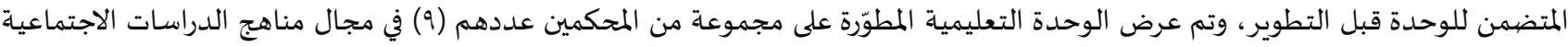

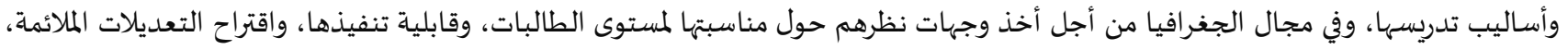

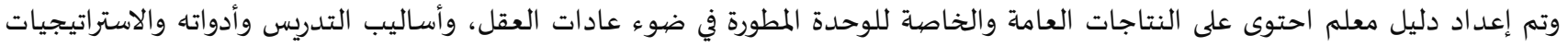

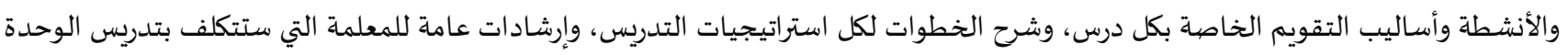

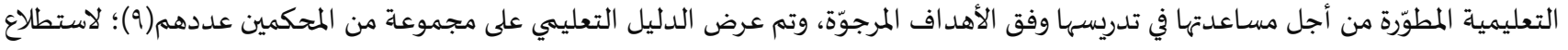

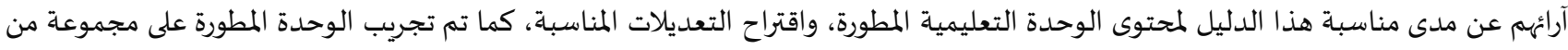

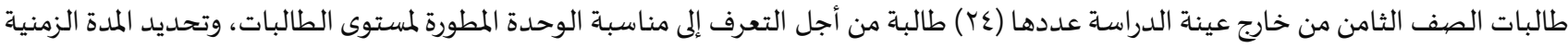

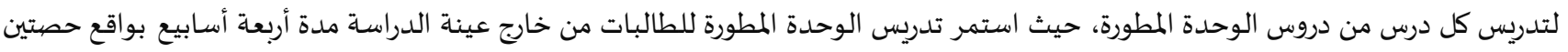

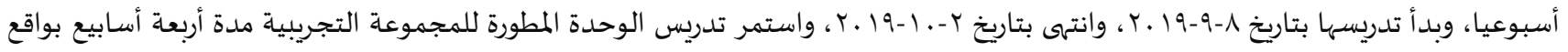

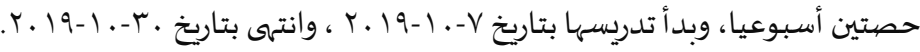

المعالجة الإحصيائية:

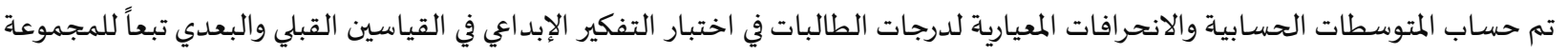

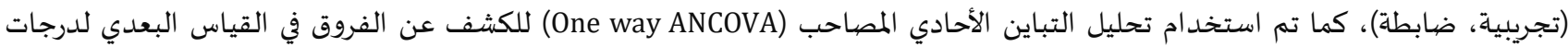
الطالبات في اختبار التفكير الإبداعي ككل وفقا للمجموعة (تجريبية، ضابطة التبانية).

نتائج الدراسة ومناقشتها: تم عرض نتائج الدراسة ومناقشتها في ضوء أسئلة الدراسة كالتالي:

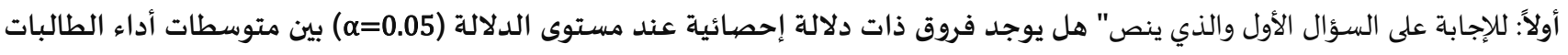

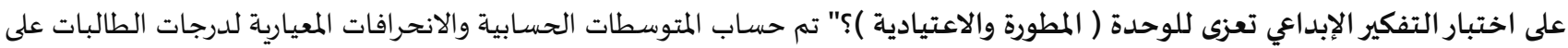

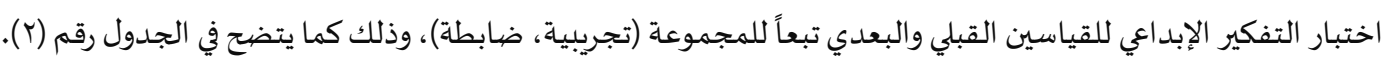
جدول (r): المتوسطات الحسابية والانحر افات المعيارية لدرجات الطالبات على اختبار التفكير الإبداعي ككل للقياسين القبلي والبعدي تبعًا للمجموعة (تجريبية، ضابطة)

\begin{tabular}{|c|c|c|c|c|c|}
\hline \multicolumn{2}{|c|}{ القياس البعدي } & \multicolumn{2}{|c|}{ القياس القبلي } & \multirow[t]{2}{*}{ العدد } & \multirow[t]{2}{*}{ المجموعة } \\
\hline الانحراف المعياري & المتوسط الحسابي & الانحراف المعياري & المتوسط الحسابي & & \\
\hline 0,0 Y0 & YN,TV & V,AKT & $r I, r T$ & $\varepsilon r$ & تجريبية \\
\hline $11, \varepsilon 79$ & $r \varepsilon, q$. & N, ITr & $r ., 11$ & $\varepsilon 1$ & ضابطة \\
\hline
\end{tabular}


يتضح من الجدول (r) وجود فروق ظاهرية بين المتوسطات الحسابية لدرجات الطالبات في اختبار التفكير الإبداعي ككل في القياسين القبلي

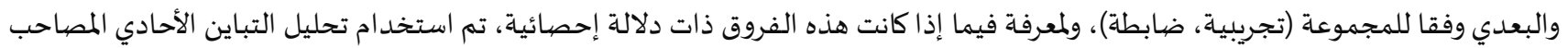
للقياس البعدي لاختبار التفكير الإبداعي وفقا للمجموعة (تجريبية، ضابطة) بعد تحييد أثر القياس القبلي لديهم، وفيما يلي عرض لهذه النتائج كما هو مبين في الجدول (r). جدول (Y): نتائج تحليل التباين الأحادي المصاحب (One way ANCOVA) للقياس البعدي لأداء أفراد الدراسة في اختبار التفكير الإبداعي ككل وفقا للمجموعة

\begin{tabular}{|c|c|c|c|c|c|c|}
\hline \multicolumn{7}{|c|}{ (تجريبية، ضيابطة) بعد تحييد أثر القياس القبلي لديهم } \\
\hline مريع & 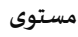 & قيمة & 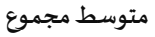 & درجات & مجموع & مصدر \\
\hline إيتاض' & الدلالة & ف & المربعات & الحرية & المربعات & التباين \\
\hline . &.,$\ldots$ & $r \cdot 10,17 \varepsilon$ & $\varepsilon 07 \varepsilon, \wedge 19$ & 1 & $\varepsilon 07 \varepsilon, 119$ & القياس القبلى \\
\hline., $0 \mathrm{VI}$ &.,$\ldots$ & $1.7, \varepsilon 1 \varepsilon$ & rTt,ANT & 1 & TrT,AMT & المجموعة \\
\hline & & & r, १M & ᄉ. & $180, .17$ & الخطأ \\
\hline & & & & NT & $\varepsilon \Lambda \Lambda V$, TAV & الكلي \\
\hline
\end{tabular}

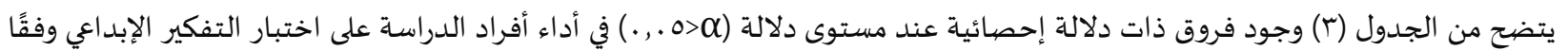

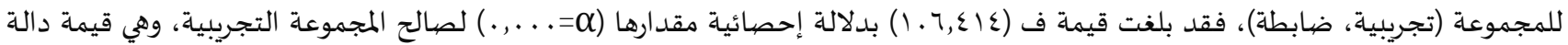
إحصائيًا، مما يعني وجود أثر للوحدة المطورة. كما يتضح من الجدول (r) أن حجم أثر الوحدة المطورة في ضوء عادات العقل كان متوسطًا طبقًا لمعايير حجم الأثر التي قدمها

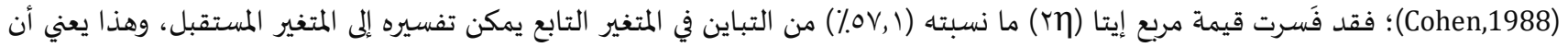

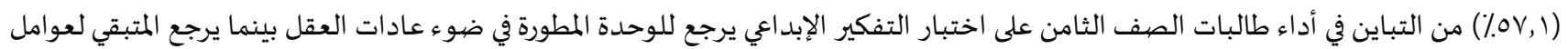
أخرى غير متحكم بها.

ولتحديد لصالح من تعزى الفروق، تم استخراج المتوسطات الحسابية المعدلة والأخطاء المعيارية لها وفقا للمجموعة، والجدول (ع) يبين ذلك.

جدول (ع): المتوسطات الحسابية المعدلة والأخطاء المعيارية في اختبار التفكير الإبداعي تبعًا للمجموعة (تجريبية، ضابطة)

\begin{tabular}{|c|c|c|}
\hline المعياري & المتوسط الحسـابي & المجمموعة \\
\hline . THA & Ү人,q). & تجرببية \\
\hline ITI & $r 1,007$ & ضابطة \\
\hline
\end{tabular}

تشير النتائج في الجدول (ع) إلى أنّ الفروق في المتوسطات الحسابية كانت لصالح المجموعة التجريبية التي تعرضت للوحدة المطورة مقارنة بأفراد

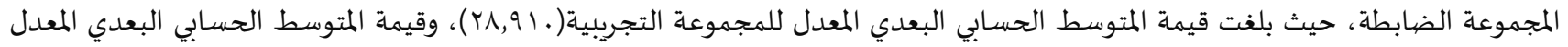

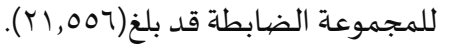

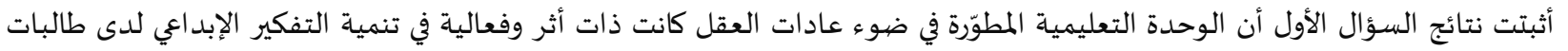

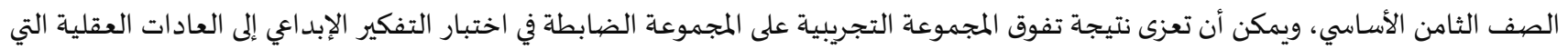
تم اختيارها وتضمينها في وحدة (العوامل الطبيعية وأثرها في السكان) من كتاب الجغرافيا وهي (عادة التفكير بمرونة، التساؤل وطرح المشكلات،

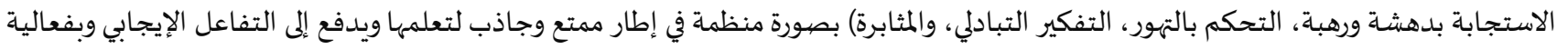

مع محتوى المادة التعليمياة.

حيث أكدت بعض الأدبيات التربوية إلى اقتران عادات العقل بالإبداع من خلال تقديمها بشكل منظم في محتوى المواد التعليمية. حيث أشار(قطامي وعمور،ه . . ب) إن المواقف والمشكلات ذات المحتوى المنظم والمقدم من خلال محتوى تعليمي لها خصائص تميزها وتجعلها ذات فائدة في

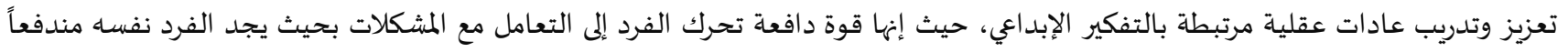
لمحاولة الحل، فمن خصائص العقل البشري أنه لا يحتمل الغموض ولا يتوقف عن المحاولة في البحث عندما يواجاه تحدي يتمثل بموقف غير مكتمل

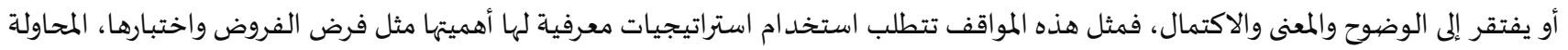

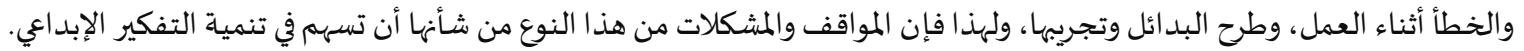

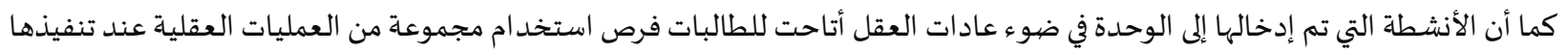

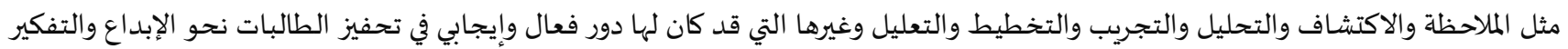
من خلال توجياء الطالبات إلى طرح العديد من الحلول للمشكلات وتقديم المزيد من الأفكار حول المواقف المقدمة. كما قد تكن هذه الأنشطة بما تحويه 
من أسئلة وصور قد ولّدت لدى الطالبات نوع من الاستثارة وعدم التوازن المعرفي للوصول إلى الأفكار والحلول فهذا قد يكون دافعاً للتفكير والبحث

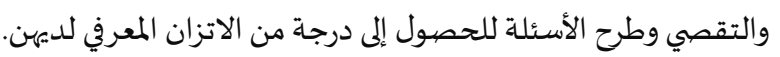

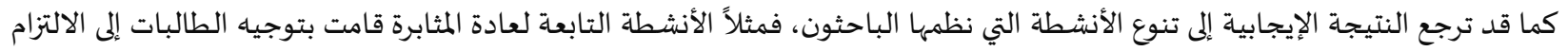

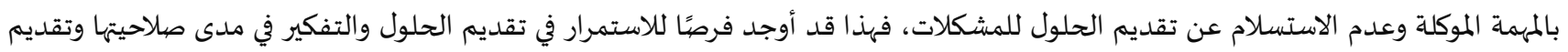

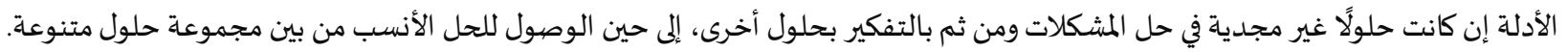

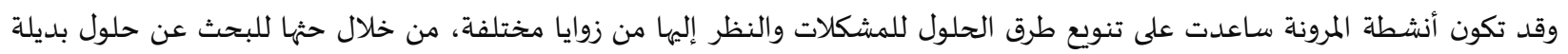

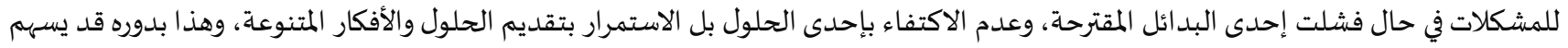

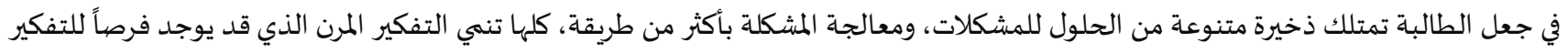

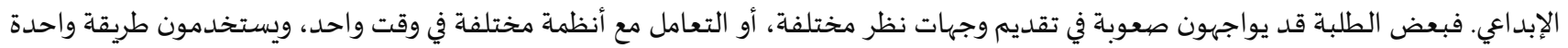

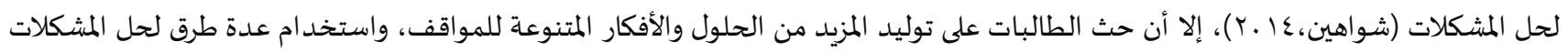

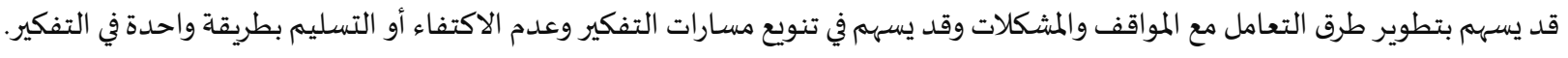

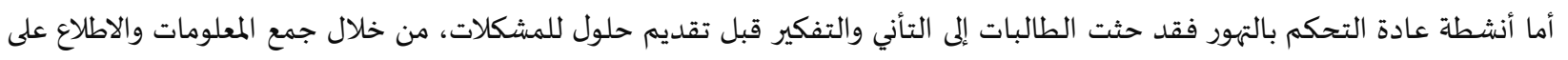

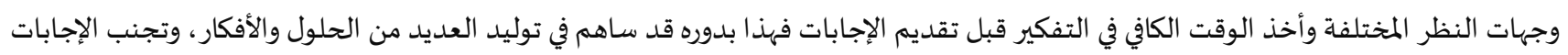

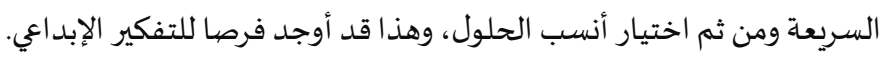

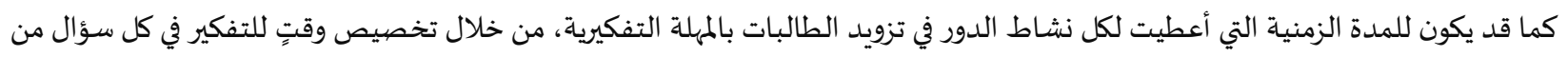

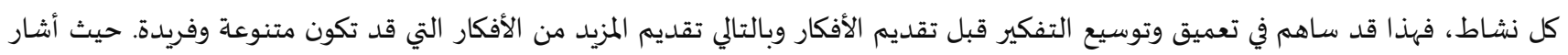

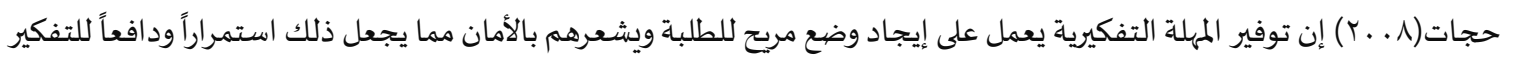

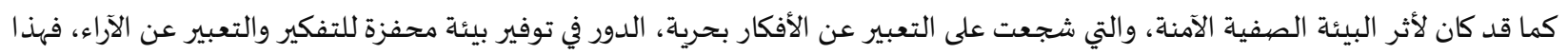

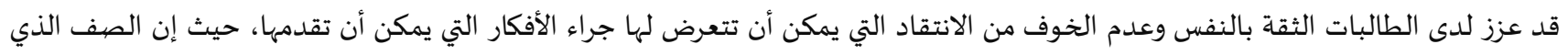

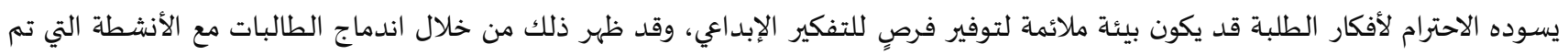
إدراجها بتقديم الأفكار بحرية، والتفاعل معها.

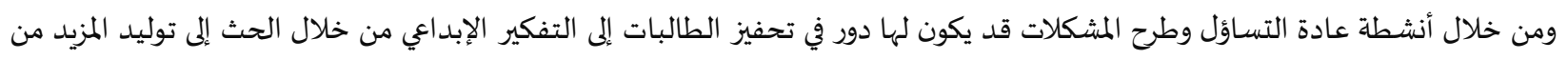

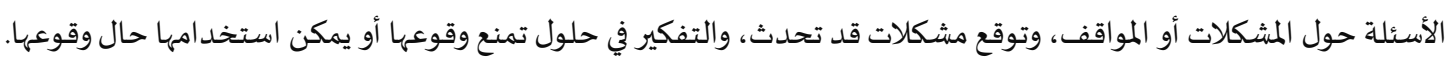

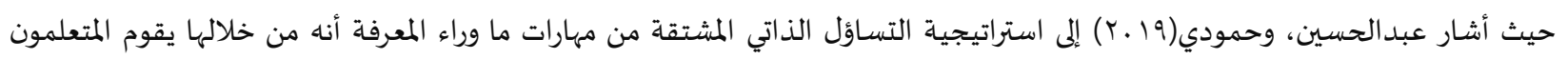

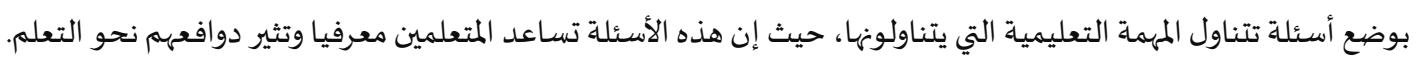

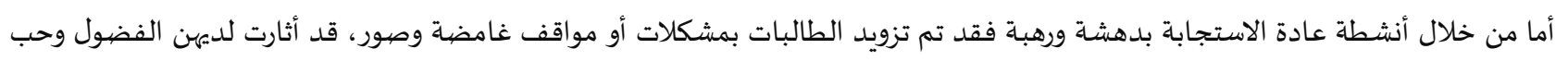

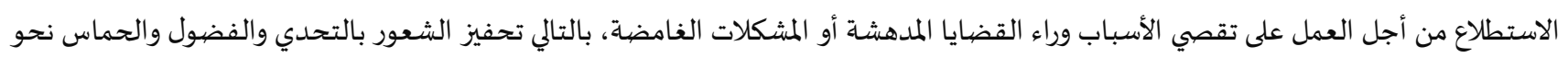
البحث عن الحلول والأسباب.

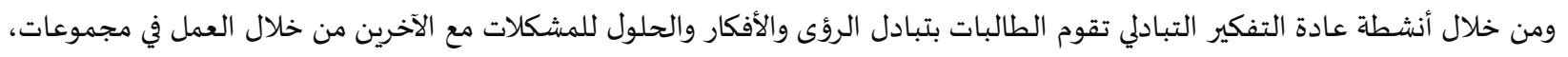

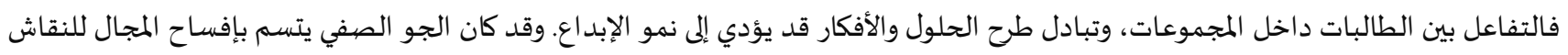

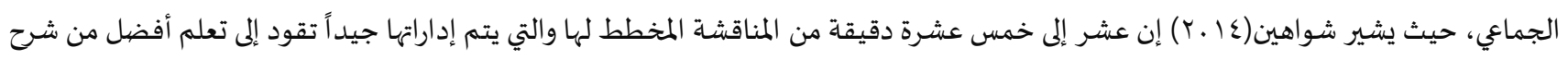

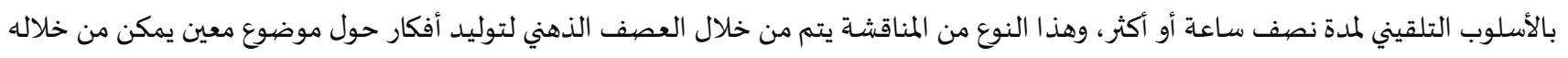

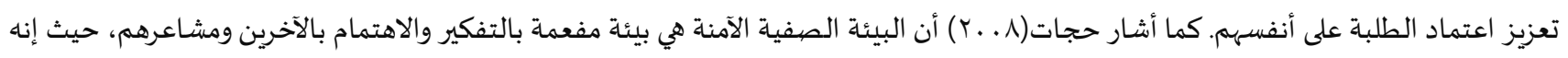

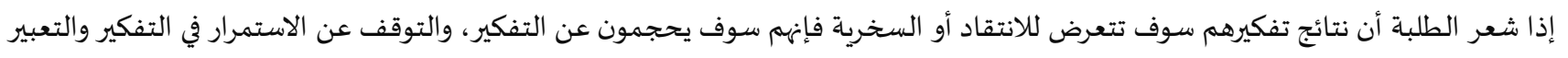
عن الأفكار.

كما قد تعزى النتيجة الإيجابية إلى طبيعة المشكلات التي تعرضت لها الطالبات من خلال أنشطة عادات العقل، وارتباطها بالواقع الذي تعيش فيها

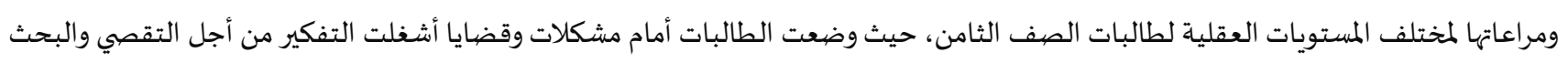

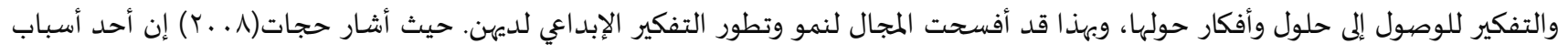

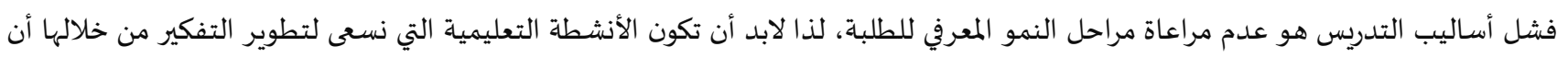

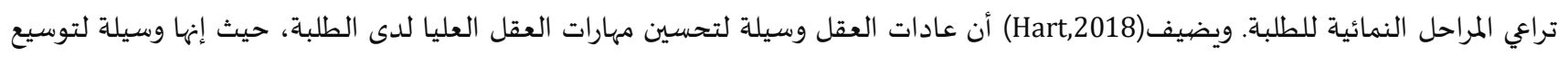
نطاق التفكير، وهي قابلة للتكيف مع مستويات متفاوتة من الطلبة. 
كما أن تنوع الأسئلة والصهور المدرجاة ضمن الأنشطة قد يكون له الأثر في تنمية التفكير، حيث إن الأنشطة احتوت عددا متنوعا من الأسئلة التي

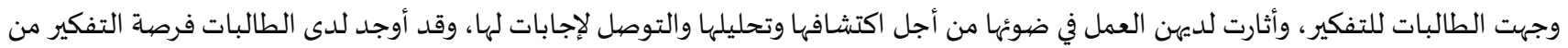

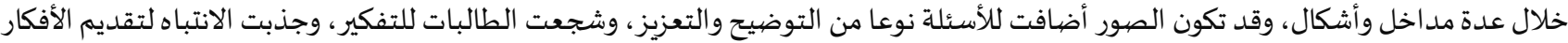
والحلول للمشكلات والمواقف المرتبطة بها.

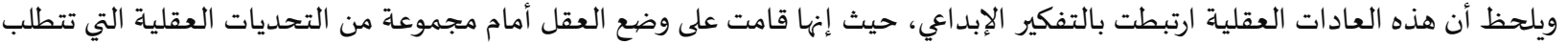

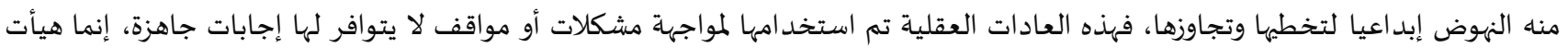

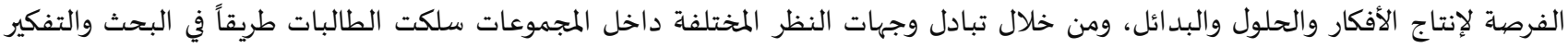

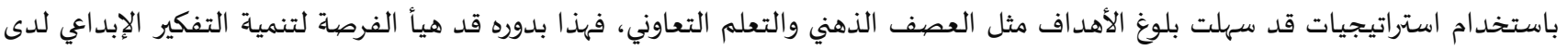

وتتفق هذه النتيجة مع نتيجة دراسة التخاينة وأبو رياش(Altakhyneh, Aburiash, 2018)، ومع دراسة الشمري(r إب) التي أوجدت علاقة

ارتباطية موجبة بين العادات العقلية والتفكير الإبداعي.

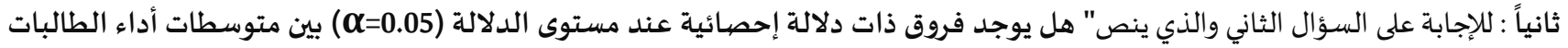

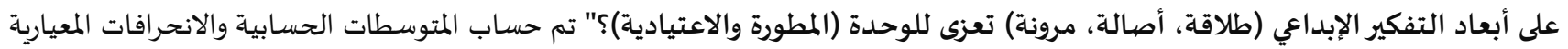

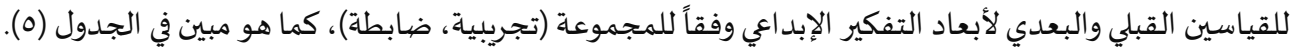

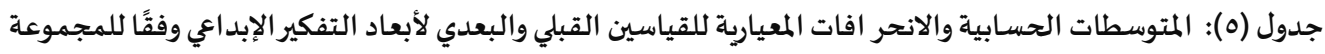

\begin{tabular}{|c|c|c|c|c|c|c|}
\hline \multicolumn{2}{|c|}{ القياس البعدي } & \multicolumn{2}{|c|}{ القياس القبلي } & \multirow[t]{3}{*}{ العدد } & \multirow[t]{3}{*}{ المجموعة } & \multirow[t]{3}{*}{ الأبعاد } \\
\hline الانحراف & الوسط & الانحراف & الوسط & & & \\
\hline المعياري & الحسابي & المعياري & الحسابي & & & \\
\hline$r, Y 00$ & $\mid r, \Lambda T$ & $r, r v$. & 9,17 & $\varepsilon r$ & تجريبية & \multirow[t]{2}{*}{ طلاقة } \\
\hline $0, r .7$ & 11,10 & $r, r) l$ & $9, \vee 1$ & \&1 & ضابطة & \\
\hline $1, V \varepsilon 1$ & $q, \varepsilon$. & T,VOA & $v, r \Lambda$ & $\varepsilon r$ & تجريبية & \multirow[t]{2}{*}{ مرونة } \\
\hline$r, \lambda \vee \wedge$ & ᄉ, 77 & $r, q \cdot V$ & $v, 09$ & «1 & ضابطة & \\
\hline $1, \varepsilon \cdot \varepsilon$ & 7,79 & $r, \varepsilon r \mid$ & $\varepsilon, 0 \mathrm{~V}$ & $\varepsilon r$ & تجريبية & \multirow[t]{2}{*}{ أصالة } \\
\hline$r, 7 \vee 7$ & 7,11 & $r, 7 \Lambda \Lambda$ & $0, . r$ & «1 & ضابطة & \\
\hline
\end{tabular}

يتضح من الجدول (0) وجود فروق ظاهرية بين المتوسطات الحسابية في القياسين القبلي والبعدي لأبعاد التفكير الإبداعي ناتج عن اختلاف المجموعة (تجريبية، ضابطة)، وبهدف التحقق من جوهرية الفروق الظاهرية، تم تطبيق تحليل التباين المصاحب الأحادي المتعدد (One Way)

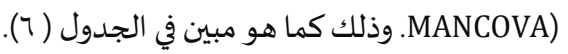

جدول (7): نتائج تحليل التباين الأحادي المتعدد المصاحب لأثر المجمموعة (تجريبية، ضابطة)على أبعاد التفكير الإبداعي ككل

\begin{tabular}{|c|c|c|c|c|c|c|c|}
\hline حجم & احتمالية & \multicolumn{2}{|c|}{ درجة حرية: } & \multirow{2}{*}{ الكلية } & \multicolumn{2}{|c|}{ تحليل التباين المتعدد المُصهاحب } & \multirow[t]{2}{*}{ الأثر } \\
\hline $\begin{array}{c}\text { الأثر } \\
\eta^{2}\end{array}$ & 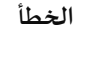 & 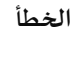 & الفرضية & & قيمته & نوع & \\
\hline., 074 & ., $\ldots$ & $\vee 7, \ldots$ & $r, \ldots$ & $r, 0.9$ & 1, זAr & Hotelling's Trace & المجموعة \\
\hline
\end{tabular}

يتبين من الجدول (7) وجود أثر للمجموعة ذي دلالة إحصائية عند مستوى الدلالة (م) . . . ) على القياس البعدي لأبعاد التفكير الإبداعي ككل

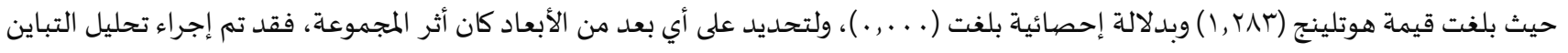

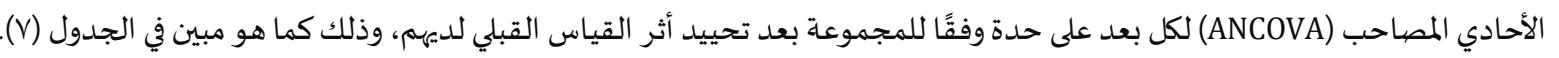

جدول (V): تحليل التباين الأحادي المصاحب (ANCOVA) وحجم الأثر لاختبار التفكير الإبداعي ككل ولكل بعد من أبعاده (طلاقة، مرونة، أصالة) بين المجموعتين في التطبيق البعدي التباري

\begin{tabular}{|c|c|c|c|c|c|c|c|}
\hline $\begin{array}{l}\text { حجم } \\
\eta^{2} \\
\eta^{2}\end{array}$ & الخطأية & ف & مجموع المربعات & الحربة & المربعات & التباين & التمتيع \\
\hline , , & , , . & $\varepsilon \Psi\}, \varepsilon, 1$ & $r Y \Lambda, . \varepsilon 1$ & 1 & $r \vee \Lambda, . \& 1$ & (المصاحب) & \multirow{3}{*}{ بعدي } \\
\hline 年, & ., $\ldots$ & $\varepsilon_{0}, ., T$ & $r \varepsilon, 7 \vee q$ & 1 & $r \varepsilon, 7 v q$ & المجموعة & \\
\hline & & & 品, & vi & 78,079 & الخطأ & \\
\hline
\end{tabular}




\begin{tabular}{|c|c|c|c|c|c|c|c|}
\hline & & & & Ar & $91,97 \varepsilon$ & الكلي & \\
\hline .,9.r & ., $\ldots$ & $V Y \Lambda, \varepsilon r q$ & ror,..1. & 1 & ror,. A. & (المصاحب) & مرونة \\
\hline \multirow[t]{3}{*}{. $, \varepsilon, \varepsilon$} & $\ldots$ & $O r, A \Sigma V$ & $\mid 1, Y 7\}$ & 1 & $|1, Y 7|$ & المجموعة & \multirow[t]{3}{*}{ بعدي } \\
\hline & & & 列, & vi & $T V, .99$ & الخطأ & \\
\hline & & & & Ar & $70 ., 191$ & الكلي & \\
\hline . A A O & ., $\ldots$ & $0 \leqslant \varepsilon, 9,9$ & 191,9 Үo & 1 & $191,9 \mathrm{ro}$ & (المصاحب) & \multirow{4}{*}{ بعدي } \\
\hline \multirow[t]{3}{*}{ 列, } & ${ }_{n}, \ldots$ & $00,9 \varepsilon \varepsilon$ & $19, v \cdot \varepsilon$ & 1 & $19, v \cdot \varepsilon$ & المجموعة & \\
\hline & & & . ror & vi & $r V, \varepsilon V T$ & الخطأ & \\
\hline & & & & NT & or.,..Vr & الكلي & \\
\hline
\end{tabular}

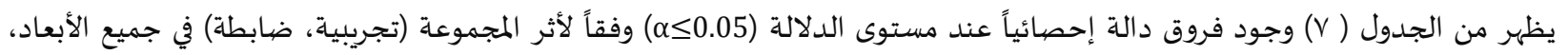

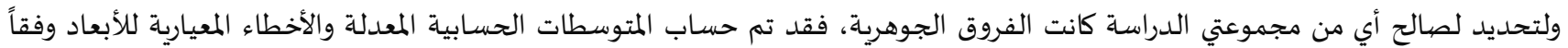
للمجموعة، كما هو مبين في الجدول ( ) ).

جدول(^): المتوسطات الحسابية المعدلة والأخطاء المعيارية للقياس البعدي لأبعاد التفكير الإبداعي وفقًا للمجموعة

\begin{tabular}{|c|c|c|c|}
\hline الخطأ المعياري & الوسط الحسابي المعدل & المجموعة & المتغير التابع \\
\hline., $1 \leq \varepsilon$ & $\mid r, \varepsilon \wedge V$ & تجريبية & \multirow[t]{2}{*}{ طلاقة-بعدي } \\
\hline., $1 \leqslant 7$ & $11,1 \wedge \varepsilon$ & ضابطة | ( بابطة & \\
\hline., .91 & $9,0 . \varepsilon$ & تجريبية & \multirow[t]{2}{*}{ مرونة-بعدي } \\
\hline., $.9 Y$ & 1,007 & ضابطة & \\
\hline .,.9Y & 7,190 & تجريبية & \multirow[t]{2}{*}{ أصالة-بعدي } \\
\hline., .94 & $0,91 \%$ & ضابطة & \\
\hline
\end{tabular}

يتضح من الجدول (م) أن الفروق الجوهرية بين المتوسطات الحسابية المعدلة للقياس البعدي في جميع أبعاد اختبار التفكير الإبداعي (طلاقة،

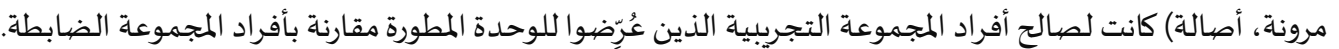

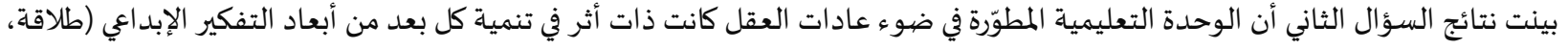

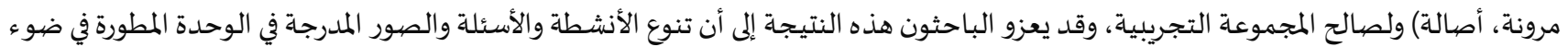

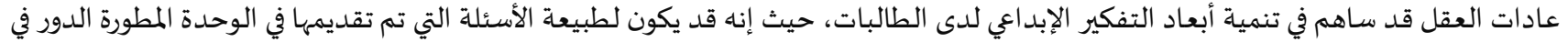

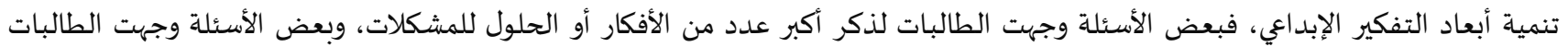

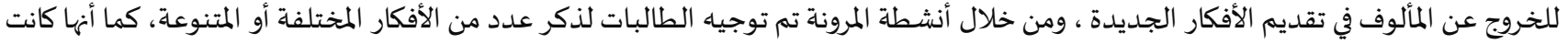

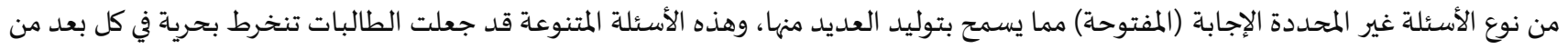
أبعاد التفكير الإبداعي.

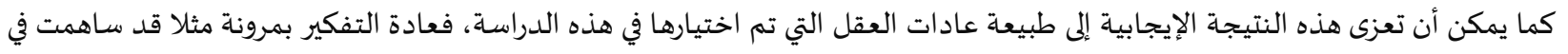

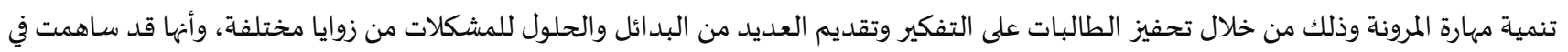

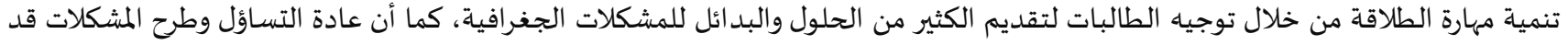

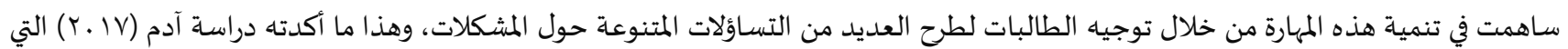

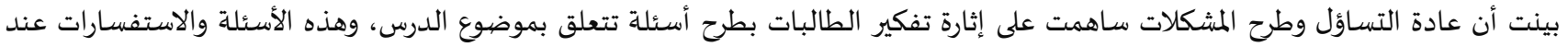

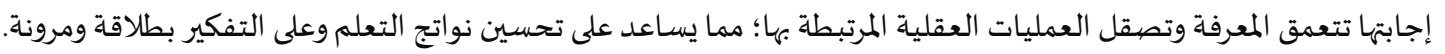

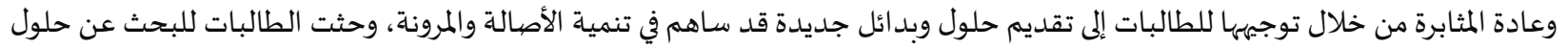

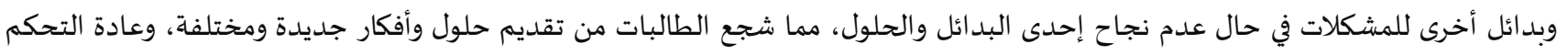

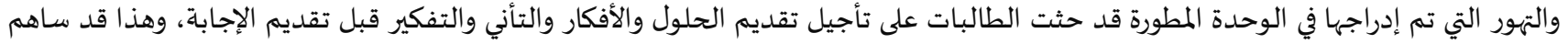

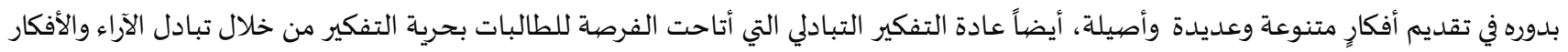
بشكل جماعي، مما أوجد العديد من الرؤى والأفكار والحلول.

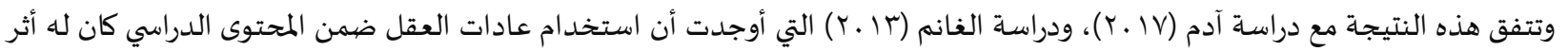

وفعالية في تنمية التفكير الإبداعي ككل، وعلى كل مهارة فرعية من مهاراته (طلاقة، أصالة، مرونة). 
في ضوء النتائج التي توصلت إليها الدراسة قدّم الباحثون مجموعة من التوصيات:

إدراج عادات العقل في مناهج الجغرافيا لما لها من دور في تنمية التفكير الإبداعي لدى الطلبة.

إدراج عادات العقل في كتب الجغرافيا للمرحلة الأسـاسية سواء التي تم تطوير الوحدة في ضوئها أو من خلال تضمين عادات أخرى غير التي وردت

في الدراسـة.

الاهتمام بنوعية الأنشطة والصور والأسئلة عند تطوير كتب الجغرافيا في ضوء عادات العقل.

المراجع:

أولاً: المراجع العربية:

1. أبازيد، أميرة. (9 أ.ب). "الكفاءة الذاتية والأداء التدريسي لمعلم الجغرافيا في تنمية عادات العقل وعلاقتها ببعض المتغيرات". مجلة الجمعية التربوية

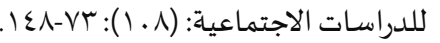

Y. إبراهيم، جمال. (ع ا . r). "استخدام نظرية تريز في تدريس الجغرافيا لتنمية عادات العقل المنتج والتفكير التقويمي لدى تلاميذ الصف الرابع الابتدائي".

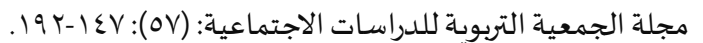

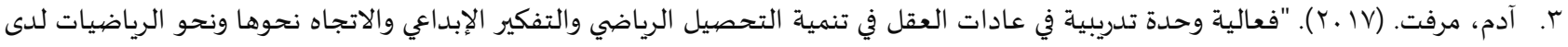

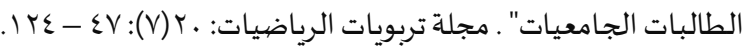

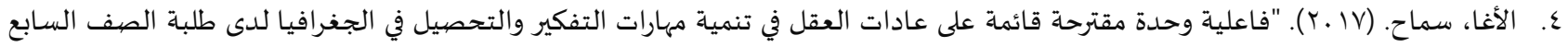
بمحافظات غزة". رسالة ماجستير غير منشورة. جامعة الأزهر. غزة.

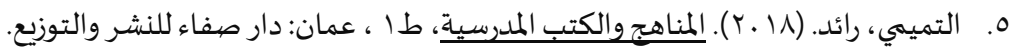

7. الجمل، عمرو. (1) ـ (Y). "فعالية استراتيجية تدريسية مقترحة قائمة على بعض عادات العقل لتلاميذ المرحلة الابتدائية في تنمية التحصيل و التفكير

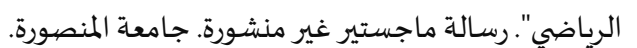

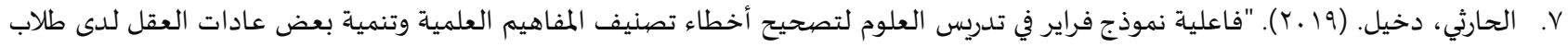

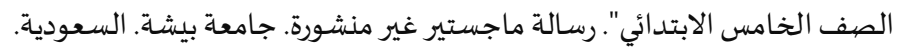

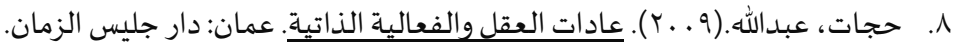

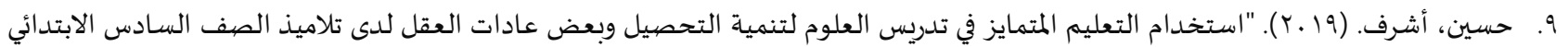

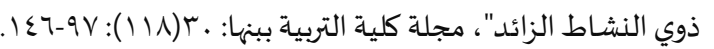
• ا. الخرشاة، سميحة. (10 ـ ب). "تطوير استراتيجية قائمة على عادات العقل لتدريس مادة الفقه الإسلامي واختبار أثرها في تحسين مهارات التفكير

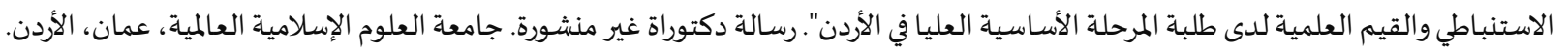
1 ا ـ خضر، فخري. (0 إب). "أثر توظيف الأنشطة الإثرائية في تنمية مهارات التفكير الإبداعي لدى طلبة الصف الثامن الأساسي في مادة الجغرافيا". دراسات

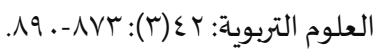

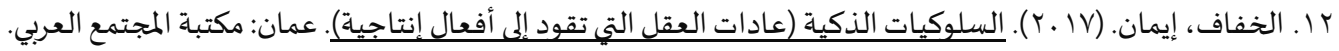

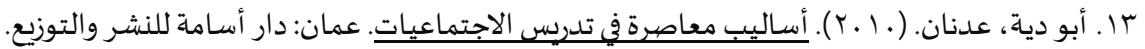

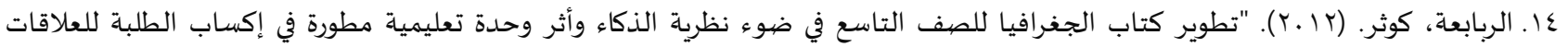

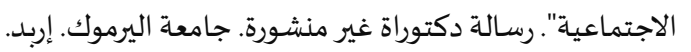

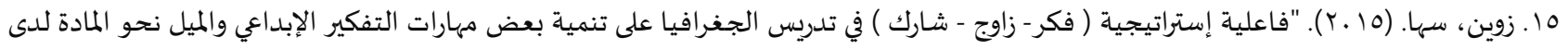

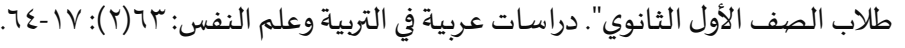

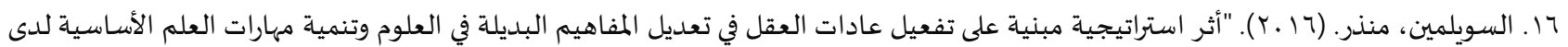

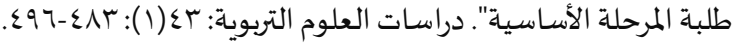

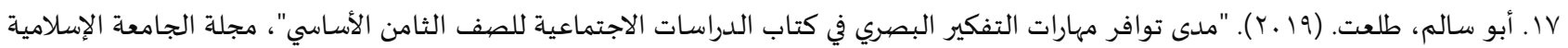

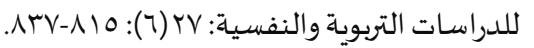

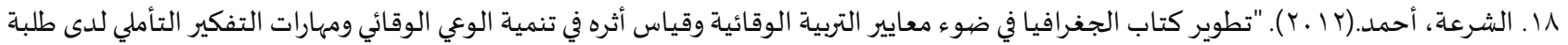

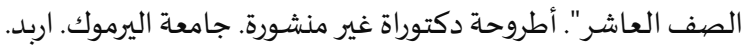


19 ـ الشمري، مشعل. (rا ـ †). "عادات العقل وعلاقتها بالتفكير الإبداعي في ضوء النوع والتخصص لدى الطلبة فائقي ومتوسطي التحصيل الدراسي بدولة الكويت". رسالة ماجستير غير منشورة. جامعة الخليج العربي. البحرين.

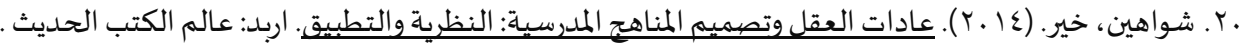

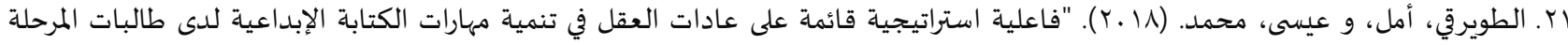

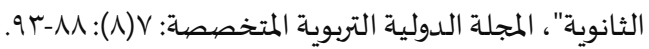

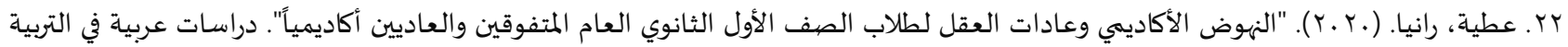

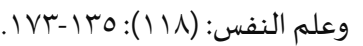

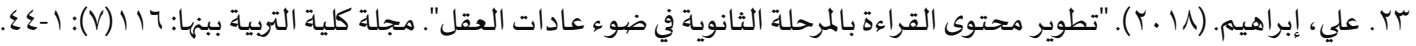

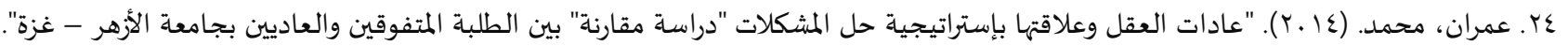

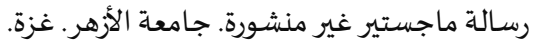

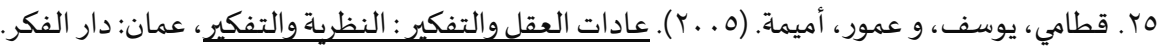

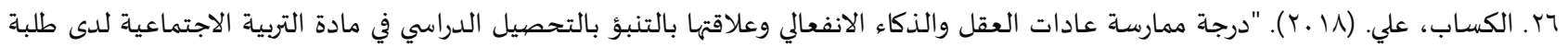

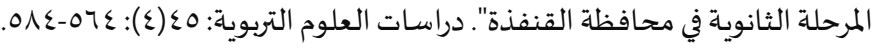

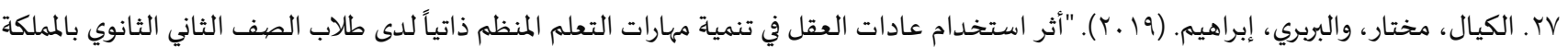

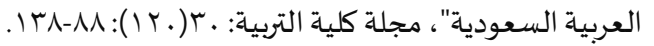

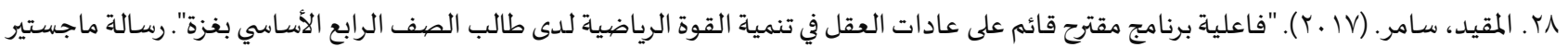
غير منشورة. الجامعة الإسلامية. غزة.

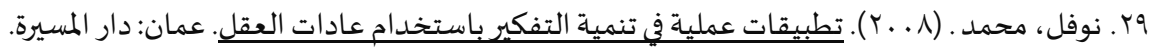

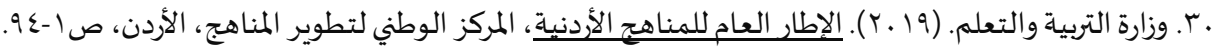

ثانياً: المراجع الاجنبية:

[1] Andriani, S., \& Yulianti, K., \& Ferdias, P., Fatonah, S. (2017). "The Effect of Mathematical Habits of Mind Learning Strategy Based on Problem Toward Students' Mathematical Creative Thinking Disposition", International E-Journal of Advances in Education, 3(9): 689-696, https://doi.org/10.18768/ijaedu.372122.

[2] Boyes, K., \& Watts, G. (2009). Developing habits of mind in secondary schools: An ASCD action tool. Alexandria, VA: ASCD.

[3] Cohen,J. (1988). Statistical power analysis for the behavioral sciences, 2ed, New York: Psychology Press.

[4] Costa, A., \&Kallick, B. (2000). Discovering and exploring habits of mind. Alexandria, VA: ASCD.

[5] Costa, A., \&Kallick, B. (2009), Habits of Mind Across the Curriculum: Practice and Creative Strategies for Teachers. Alexandria, Va: ASCD.

[6] Hafni,R., \& Sari,D., \& Nurlaelah,E. (2018). "Analyzing theeffect of students' habits of mind to mathematical critical thinking skill”. Journal of Physics, 1211 (1), https://doi.org/10.1088/1742-6596/1211/1/012074.

[7] Hart, N. (2018). "Habits of Mind and Comprehension: A Teacher 'S Resource for Standards-Based Integration with A Growth Mindset”, Unpublished Master's Thesis, Hamline University Saint Paul, Minnesota.

[8] John,F. (2000). "The Quality Assurance Agency's Benchmark Statement for Geography". Journal of Geography in Higher Education. 24(3): 399-412, https://doi.org/10.1080/713677419.

[9] Kallick, B. \&Zmuda,A. (2017). Students at the center: personalized learning with habits of mind. Alexandria, Virginia: ASCD.

[10] Altakhyneh,B. \& Aburiash, H. (2018). "Impact of Habits of Mind in Mathematical Creative Thinking at Amman Schools", An - Najah Univ. J. Res. (Humanities), 32(2): 418- 438, https://doi.org/10.35552/0247-032-002-008. 


$$
\text { المجلة الدولية للدراسـات التربوية والنفسية }
$$

International Journal of Educational \& Psychological Studies (EPS)

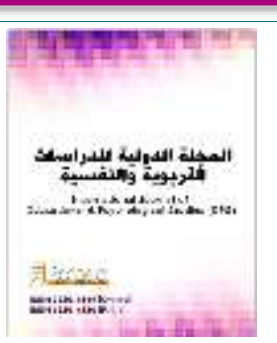

\title{
Developing an instructional unit in geography textbook for the eighth grade in light of habits of mind and measuring its effect on female students creative thinking in Jordan
}

\author{
1Doaa Khalil Abu Saada, 2 Samih Mahmoud Al- Karasneh, ${ }^{3}$ Ghazi Daffallah Rawagah \\ ${ }^{1} \mathrm{PhD}$ student, College of Education, Yarmouk University, Jordan \\ 2 Professor of Social Studies Curricula, College of Education, Yarmouk University, Jordan \\ 3 Professor of Curricula and Methods of Teaching Comprehensive Professional Education, College of Education, \\ Yarmouk University, Jordan \\ ${ }^{1}$ doaa.saada88@yahoo.com, ${ }^{2}$ s.m.karasneh@yu.edu.jo, ${ }^{3}$ Ghazi.Rawagah@yu.edu.jo
}

Received : 24/2/2020 Revised : 13/3/2020 Accepted : 20/3/2020 DOI : https://doi.org/10.31559/EPS2020.8.3.5

Abstract: The study aimed to developing an instructional unit from geography textbook for the eighth grade in light of habits of mind and measuring its effect on female students creative thinking in Jordan during the first semester 2019/2020. To achieve the aims of the study, a semi-experimental approach was adopted. the Creative thinking Test were prepared. The study sample was formed of (83) female students, assigned randomly into two study groups, the first is experimental group consisting of (42), and the second is control group consisting of (41). The results showed that there are statistically significant differences in the scores of students in the test of creative thinking, and for the benefit of the experimental group attributed to the unit developed according to habits of mind, and some recommendations were suggested.

Keywords: Developing an Instructional Unit; Habits of Mind; Creative Thinking.

\section{References:}

[1] 'ly, Ebrahym. (2018). "Ttwyr Mhtwa Alqra'h Balmrhlh Althanwyh Fy Dw' 'adat Al'ql". Mjlt Klyt Altrbyh Bbnha: 116(7): 144.

[2] 'mran, Mhmd. (2014). "'Eadat Al'ql W'laqtha Bestratyjyh Hl Almshklat "Drash Mqarnh" Byn Altlbh Almtfwqyn Wal'adyyn Bjam't Alazhr - Ghzh". Rsalt Majstyr Ghyr Mnshwrh. Jam't Alazhr. Ghzh.

[3] 'tyh, Ranya. (2020). "Alnhwd Alakadymy W'adat Al'ql Ltlab Alsf Alawl Althanwy Al'am Almtfwqyn Wal'adyyn Akadymyaan". Drasat 'rbyh Fy Altrbyh W'Im Alnfs: (118): 135-173.

[4] Abazyd, Amyrh. (2019). "Alkfa'h Aldatyh Walada' Altdrysy Lm'lm Aljghrafya Fy Tnmyt 'adat Al'ql W'laqtha Bb'd Almtghyrat". Mjlt Aljm'yh Altrbwyh Lldrasat Alajtma'yh: (108): 73-148.

[5] Adm, Mrft. (2017). "F'alyt Whdt Tdrybyh Fy 'adat Al'ql Fy Tnmyh Althsyl Alryady Waltfkyr Alebda'y Walatjah Nhwha Wnhw Alryadyat Lda Altalbat Aljam'yat". Mjlt Trbwyat Alryadyat: 20(7): 47 - 124.

[6] Alagha, Smah. (2017). "Fa'lyt Whdt Mqtrhh Qaemh 'la 'adat Al'ql Fy Tnmyt Mharat Altfkyr Walthsyl Fy Aljghrafya Lda Tlbh Alsf Alsab' Bmhafzat Ghzh". Rsalt Majstyr Ghyr Mnshwrh. Jam't Alazhr. Ghzh.

[7] Abw Dyh, 'dnan. (2010). Asalyb M'asrh Fy Tdrys Alajtma'yat. 'man: Dar Asamh Llnshr Waltwzy'.

[8] Ebrahym, Jmal. (2014). "Astkhdam Nzryt Tryz Fy Tdrys Aljghrafya Ltnmyh 'adat Al'ql Almntj Waltfkyr Altqwymy Lda Tlamyd Alsf Alrab' Alabtda'y". Mjlt Aljm'yh Altrbwyh Lldrasat Alajtma'yh: (57): 147-192.

[9] Alharthy, Dkhyl. (2019). "Fa'lyt Nmwdj Frayr Fy Tdrys Al'lwm Ltshyh Akhta' Tsnyf Almfahym Al'lmyh Wtnmyh B'd 'Eadat Al'ql Lda Tlab Alsf Alkhams Alabtda'y". Rsalt Majstyr Ghyr Mnshwrh. Jam't Byshh. Als'wdyh.

[10] Hjat, 'bdallh.(2009). 'adat Al'ql Walf'alyh Aldatyh. 'man: Dar Jlys Alzman.

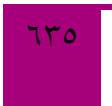

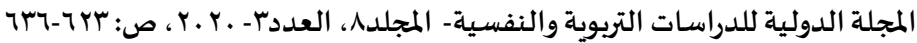


[11] Hsyn, Ashrf. (2019). "Astkhdam Alt'lym Almtmayz Fy Tdrys Al'lwm Ltnmyh Althsyl Wb'd 'adat Al'ql Lda Tlamyd Alsf Alsads Alabtda'ey Dwy Alnshat Alza'd", Mjlt Klyh Altrbyh Bbnha: 30 (118): 97-146.

[12] Aljml, 'mrw. (2018). "F'alyt Astratyjyh Tdrysyh Mqtrhh Qa'mh 'la B'd 'adat Al'ql Ltlamyd Almrhlh Alabtda'yh Fy Tnmyt Althsyl W Altfkyr Alryady". Rsalt Majstyr Ghyr Mnshwrh. Jam't Almnswrh.

[13] Khdr, Fkhry. (2015). "Athr Twzyf Alanshth Alethra'yh Fy Tnmyt Mharat Altfkyr Alebda'y Lda Tlbh Alsf Althamn Alasasy Fy Madt Aljghrafya". Drasat Al'lwm Altrbwyh: 42(3): 873-890.

[14] Alkhfaf, Eyman. (2017). Alslwkyat Aldkyh ('adat Al'ql Alty Tqwd Ela Af'al Entajyh). 'man: Mktbh Almjtm' Al'rby.

[15] Alkhrshh, Smyhh. (2015). "Ttwyr Astratyjyh Qa'mh 'la 'Eadat Al'ql Ltdrys Madh Alfqh Aleslamy Wakhtbar Athrha Fy Thsyn Mharat Altfkyr Alastnbaty Walqym Al'lmyh Lda Tlbt Almrhlh Alasasyh Al'lya Fy Alardn". Rsalt Dktwrah Ghyr Mnshwrh. Jam't Al'lwm Aleslamyh Al'almyh, 'man, Alardn.

[16] Alksab, 'Ely. (2018). "Drjt Mmarsh 'adat Al'ql Waldka' Alanf'aly W'laqtha Baltnb' Balthsyl Aldrasy Fy Madt Altrbyh Alajtma'yh Lda Tlbt Almrhlh Althanwyh Fy Mhafzh Alqnfdh". Drasat Al'lwm Altrbwyh: 45(4): 564-584.

[17] Alkyal, Mkhtar, Walbrbry, Ebrahym. (2019). "Athr Astkhdam 'adat Al'ql Fy Tnmyh Mharat Alt'lm Almnzm Datyaan Lda Tlab Alsf Althany Althanwy Balmmlkh Al'erbyh Als'wdyh", Mjlt Klyh Altrbyh: 30(120): 88-138.

[18] Almqyd, Samr. (2017). "Fa'lyt Brnamj Mqtrh Qa'm 'la 'adat Al'ql Fy Tnmyh Alqwh Alryadyh Lda Talb Alsf Alrab' Alasasy Bghzh". Rsalt Majstyr Ghyr Mnshwrh. Aljam'h Aleslamyh. Ghzh.

[19] Nwfl, Mhmd . (2008). Ttbyqat 'mlyh Fy Tnmyt Altfkyr Bastkhdam 'adat Al'ql. 'man: Dar Almsyrh.

[20] Qtamy, Ywsf, W 'mwr, Amymh. (2005). 'adat Al'ql Waltfkyr : Alnzryh Waltfkyr, 'man: Dar Alfkr.

[21] Alrbab'h, Kwthr. (2012). "Ttwyr Ktab Aljghrafya Llsf Altas' Fy Dw' Nzryh Aldka' Wathr Whdh T'lymyh Mtwrh Fy Eksab Altlbh Ll'laqat Alajtma'yh". Rsalt Dktwrah Ghyr Mnshwrh. Jam't Alyrmwk. Erbd.

[22] Abw Salm, Tl'et. (2019). "Mda Twafr Mharat Altfkyr Albsry Fy Ktab Aldrasat Alajtma'yh Llsf Althamn Alasasy", Mjlt Aljam'h Aleslamyh Lldrasat Altrbwyh Walnfsyh: 27(6): 815-837.

[23] Alshmry, Msh'l. (2013). "'Eadat Al'ql W'laqtha Baltfkyr Alebda'y Fy Dw' Alnw' Waltkhss Lda Altlbh Fa'qy Wmtwsty Althsyl Aldrasy Bdwlh Alkwyt". Rsalt Majstyr Ghyr Mnshwrh. Jam't Alkhlyj Al'rby. Albhryn.

[24] Alshr'h, Ahmd. (2012). "Ttwyr Ktab Aljghrafya Fy Dw' M'ayyr Altrbyh Alwqa'yh Wqyas Athrh Fy Tnmyt Alw'y Alwqa'y Wmharat Altfkyr Altamly Lda Tlbh Alsf Al'ashr". Atrwht Dktwrah Ghyr Mnshwrh. Jam't Alyrmwk. Arbd.

[25] Shwahyn, Khyr. (2014). 'adat Al'ql Wtsmym Almnahj Almdrsyh: Alnzryh Walttbyq. Arbd: 'alm Alktb Alhdyth.

[26] Alswylmyn, Mndr. (2016). "Athr Astratyjyh Mbnyh 'la Tf'eyl 'adat Al'ql Fy T'dyl Almfahym Albdylh Fy Al'lwm Wtnmyh Mharat Al'Im Alasasyh Lda Tlbt Almrhlh Alasasyh". Drasat Al'lwm Altrbwyh: 43(1): 483-496.

[27] Altmymy, Ra'd. (2018). Almnahj Walktb Almdrsyh, T1, 'man: Dar Sfa' Llnshr Waltwzy'.

[28] Altwyrqy, Aml, W 'Eysa, Mhmd. (2018). "Fa'lyt Astratyjyh Qa'mh 'la 'adat Al'ql Fy Tnmyh Mharat Alktabh Alebda'yh Lda Talbat Almrhlh Althanwyh", Almjlh Aldwlyh Altrbwyh Almtkhssh: 7(8): 88-93.

[29] Wzart Altrbyh Walt'elm. (2019). Aletar Al'am Llmnahj Alardnyh, Almrkz Alwtny Lttwyr Almnahj, Alardn, S1-94.

[30] Zwyn, Sha. (2015). "Fa'lyt Estratyjyh (Fkr- Zawj - Shark) Fy Tdrys Aljghrafya 'la Tnmyh B'd Mharat Altfkyr Alebda'y Walmyl Nhw Almadh Lda Tlab Alsf Alawl Althanwy". Drasat 'Erbyh Fy Altrbyh W'lm Alnfs: 63(2): 17-64. 